\title{
Deuterium trapping by deformation-induced defects in tungsten
}

\author{
M. Zibrov ${ }^{1,2,3}$, M. Balden ${ }^{1}$, M. Dickmann ${ }^{4,5}$, A. Dubinko ${ }^{6}$, \\ W. Egger ${ }^{4}$, M. Mayer ${ }^{1}$, D. Terentyev ${ }^{6}$, M. Wirtz ${ }^{7}$ \\ ${ }^{1}$ Max-Planck-Institut für Plasmaphysik, Boltzmannstrasse 2, 85748 Garching, \\ Germany \\ ${ }^{2}$ Physik-Department E28, Technische Universität München, James-Franck-Strasse 1, \\ 85748 Garching, Germany \\ ${ }^{3}$ Department of Applied Physics, Ghent University, Sint-Pietersnieuwstraat 41, 9000 \\ Ghent, Belgium \\ ${ }^{4}$ Institut für Angewandte Physik und Messtechnik, Universität der Bundeswehr \\ München, Werner-Heisenberg-Weg 39, 85577 Neubiberg, Germany \\ ${ }^{5}$ Heinz Maier-Leibnitz Zentrum (MLZ) and Physik-Department E21, Technische \\ Universität München, Lichtenbergstrasse 1, 85748 Garching, Germany \\ ${ }^{6}$ Institute of Nuclear Material Sciences, SCK•CEN, Boeretang 200, $2400 \mathrm{Mol}$, \\ Belgium \\ ${ }^{7}$ Institut für Energie- und Klimaforschung, Forschungszentrum Jülich GmbH, 52425 \\ Jülich, Germany \\ E-mail: Mikhail.Zibrov@ipp.mpg.de
}

\begin{abstract}
The influence of defects induced by plastic deformation of tungsten (W) on deuterium (D) retention has been studied. Recrystallized W samples were subjected to tensile deformations at temperatures of $573 \mathrm{~K}$ and $873 \mathrm{~K}$ to strains in the range of 3-38\%. The dislocation density measured by transmission electron microscopy (TEM) increased by about 40 times after deformation to the highest strain. The introduced defects were decorated with $\mathrm{D}$ by exposure to a low-flux $\mathrm{D}$ plasma at sample temperatures of $370 \mathrm{~K}$ and $450 \mathrm{~K}$. D retention in the samples was studied using nuclear reaction analysis (NRA) and thermal desorption spectroscopy (TDS). The trapped D concentrations after the plasma exposures were low (up to a few times $10^{-4}$ at. fr.) and increased more slowly with strain than the dislocation density. Small vacancy-like defects and large vacancy clusters were detected in the samples by positron annihilation lifetime spectroscopy (PALS). Their concentrations also increased with strain more weakly than the dislocation density. It was concluded that these defects governed the $\mathrm{D}$ retention under plasma exposure at $450 \mathrm{~K}$, while dislocations gave only a small contribution. It was also found that deformation already to the lowest strains significantly facilitates the formation of blister-like structures under D plasma exposure at $370 \mathrm{~K}$. The defects associated with blister-like structures presumably gave a substantial contribution to $\mathrm{D}$ retention at $370 \mathrm{~K}$.
\end{abstract}

Keywords: Tungsten, Deuterium retention, Dislocations, Plastic deformation Published in: Nuclear Fusion 59 (2019) 106056 


\section{Introduction}

Retention of hydrogen $(\mathrm{H})$ isotopes (especially of radioactive tritium) in plasma-facing materials (PFMs) in magnetic confinement fusion devices is an issue both from the safety and economic points of view. Tungsten (W) will be used as a PFM in the divertor of ITER [1, 2] and is also likely to be used as the divertor and the first wall material in DEMO and future fusion devices [3]. It is well established that $\mathrm{H}$ isotope retention in $\mathrm{W}$ is governed by the trapping in lattice defects [3, 4]. Dislocations are common defects in $\mathrm{W}$ as large amounts of dislocations are introduced during the manufacturing process [5, 6]. Furthermore, dislocations can also be formed in W components during transient events (e.g., edge localized modes) via a plastic deformation caused by high thermal stresses [1, 3]. Stresses caused by high local concentrations of solute $\mathrm{H}$ during plasma operation can also induce a plastic deformation [7, 8, 9].

Although $\mathrm{H}$ interactions with dislocations have been extensively studied for various metals and alloys [10], the data for $\mathrm{W}$ is scarce. In the experiments of Ogorodnikova et al. [11] defects with a rather low $\mathrm{H}$ detrapping energy of $0.85 \mathrm{eV}$ were attributed to dislocations and grain boundaries. Concurrently, Manhard [12] ascribed defects with the $\mathrm{H}$ detrapping energy of $1.25 \pm 0.11 \mathrm{eV}$ to dislocations. Anderl et al. [13] observed a correlation between the reduction of the concentration of defects with the $\mathrm{H}$ detrapping energies in the range of $1.34-1.56 \mathrm{eV}$ and the reduction of the dislocation density, although it was admitted that these energies seem to be too high for dislocations. Density functional theory (DFT) calculations [14, 15, 16] predict different H detrapping energies for various types of dislocations in W: An edge dislocation has a considerably higher $\mathrm{H}$ detrapping energy $(1.28-1.36 \mathrm{eV})$ compared with that of a screw dislocation $(0.92-0.96 \mathrm{eV}) \mathrm{f}$.

Most of the previous experimental studies on this subject employed annealing of as-received dislocation-rich $\mathrm{W}$ samples at various temperatures, which resulted in the decrease of dislocation density, and investigated its influence on deuterium (D) trapping [11, 12, 13]. However, apart from the reduction of the dislocation density, recovery of other defect types, recrystallization, grain growth, redistribution (e.g., segregation at grain boundaries) and partial removal of impurities occur in the course of annealing [5, 6, 18. This hampers an unambiguous identification of the role of dislocations. An alternative approach was recently utilized by Terentyev and co-workers [19, 20] where recrystallized $\mathrm{W}$ specimens were subjected to a tensile plastic deformation in order to introduce dislocations. However, the samples were then exposed to divertor-relevant high fluxes of low-energy D ions, which resulted in emergence of blister-like structures on the surfaces of the samples. It is known that the appearance of blisters leads to the introduction of additional trapping sites for $\mathrm{D}$ in the subsurface region of $\mathrm{W}$ [12, 21, 22]. These traps can easily govern the D retention, which complicates the interpretation of the results.

$\ddagger$ The detrapping energy is calculated as the sum of the $\mathrm{H}$ binding energy to a dislocation core derived from DFT and the activation energy for $\mathrm{H}$ diffusion in $\mathrm{W}$ of $0.39 \mathrm{eV}$ reported by Frauenfelder [17. 
The present contribution is devoted to the investigation of D retention in plasticallydeformed $\mathrm{W}$ samples with various dislocation densities after a low-flux D plasma exposure, allowing to reduce considerably the amount of defects introduced during the plasma exposure.

\section{Experimental details}

\subsection{The samples}

Hot-rolled polycrystalline $\mathrm{W}$ with a purity of 99.97 wt. \% manufactured by Plansee (Austria) was used. A number of flat dog bone-shaped tensile specimens with an overall length of $120 \mathrm{~mm}$ and gauge section dimensions of $50 \times 13 \times 0.8 \mathrm{~mm}^{3}$ were cut by spark erosion from a single plate of the material. In order to minimise the density of dislocations, grain boundaries, and gaseous impurities, the tensile samples were recrystallized at $1873 \mathrm{~K}$ for $1 \mathrm{~h}$ in vacuum $(0.02-0.05 \mathrm{~Pa})$ at Forschungszentrum Jülich. To cover a wide range of dislocation densities, interrupted uniaxial tensile tests were carried out at two sample temperatures to three different engineering strains: low ( $3 \%$ at $573 \mathrm{~K}$ and $5 \%$ at $873 \mathrm{~K}$ ), medium ( $20 \%$ at $573 \mathrm{~K}$ and $22 \%$ at $873 \mathrm{~K}$ ), and high ( $36 \%$ at $573 \mathrm{~K}$ and $38 \%$ at $873 \mathrm{~K}$ ). It should be noted that the stresses corresponding to high strains are close to the ultimate tensile strength of the studied W grade at the respective deformation temperatures. The tensile tests were performed in air at $\mathrm{SCK} \bullet \mathrm{CEN}$. The displacement rate was $0.2 \mathrm{~mm} / \mathrm{min}$, corresponding to a strain rate of $6.7 \times 10^{-5} \mathrm{~s}^{-1}$. The whole gauge section of each sample was homogeneously deformed since no local necking was formed even at the highest strain applied (see Fig. S1 in the supplementary material).

The samples for D retention studies with linear dimensions of $10 \times 10 \mathrm{~mm}^{2}$ were

cut by spark erosion from the gauge sections of the tensile specimens. The reference (undeformed) samples were cut from the grip sections of the tensile specimens, which did not experience deformation during the tests. The obtained samples were first ground with a set of $\mathrm{SiC}$ sandpapers with decreasing abrasive grit sizes (up to P4000), which allowed to remove the oxide layer developed during the tensile test. Then they were electrochemically polished to a mirror-like finish in a $1.5 \mathrm{wt} . \% \mathrm{NaOH}$ aqueous solution in order to remove the distorted near-surface layer introduced during grinding [23]. Afterwards, the samples were successively cleaned in an ultrasonic bath with acetone, isopropanol, and a high-purity acetone and then rinsed in deionized water.

\subsection{Microscopy}

The surface morphology of the samples was investigated in a confocal laser scanning microscope (CLSM) Olympus LEXT OLS4000 and a scanning electron microscope (SEM) FEI HELIOS NanoLab 600 at IPP. The structure of sub-surface features was studied using SEM in combination with focused ion beam (Ga) cross-sectioning. Prior to cutting, the region of interest was coated with a Pt-C layer. The cross-sections are 
imaged at $38^{\circ}$ tilt making the vertical scales appear compressed by a factor of 1.27 with respect to the horizontal scales.

The grain structure of the samples was examined using the backscattered electron (BSE) SEM images, which have high crystal orientation (channelling) contrast. The incident electron energy was $5 \mathrm{keV}$. Quantitative analysis of grain orientations was carried out using electron backscatter diffraction (EBSD) with $20 \mathrm{keV}$ electrons impacting under an angle of $57^{\circ}$. The comparison of sensitivities of BSE imaging and EBSD to grain orientation variations is illustrated in Fig. 1 for the same area of the sample strained to $38 \%$ at $873 \mathrm{~K}$. BSE images allow to reveal very small orientation variations (tenths of a degree) that cannot be detected by EBSD. Contrary to EBSD, the observed orientation variations in BSE images cannot be quantified and can be easily overinterpreted, for instance, in terms of identification of low- and high-angle grain boundaries.

The dislocation microstructure of the samples was investigated using transmission electron microscopy (TEM). Two samples with linear dimensions of $2.4 \times 10 \mathrm{~mm}^{2}$ were cut by spark erosion from the central part of the gauge sections of the tensile specimens. These samples were first ground from both sides to reduce their thickness to 100$130 \mu \mathrm{m}$ and then cut into pieces $\left(2.4 \times 2.4 \mathrm{~mm}^{2}\right)$ with a diamond wire saw. Afterwards, they were glued on TEM grids and then electrochemically thinned from both sides using 1.5 wt. $\% \mathrm{NaOH}$ aqueous solution until a small hole appeared in the centre of the sample. The specimens were investigated with a JEOL 3010 TEM operating at $300 \mathrm{kV}$ at SCK•CEN. The TEM images were acquired in bright field imaging mode. The average dislocation density defined as the total length of dislocation lines per unit volume was determined using Ham's interception method [24]. In this method, a circle is drawn randomly in a TEM image and the number of intersections with dislocations is counted using the Gatan DigitalMicrograph 3 software. The dislocation density is then computed as $\rho=2 N /(L t)$, where $N$ is the number of intersections of the circle with dislocation lines, $L$ is the circumference of the circle, and $t$ is the local sample thickness determined from the convergent beam electron diffraction pattern analysis. Only dislocations present in the grain interior were counted; dense dislocation agglomerations near grain boundaries and dislocation walls were not taken into account. Hence, the given dislocation densities should be considered as a lower limit for the total dislocation density. Several calculations at different regions of the sample were carried out in order to obtain the average value of the dislocation density in the grain interior.

\subsection{Positron annihilation lifetime spectroscopy}

The presence of small open-volume defects not observable in TEM, such as jogs on dislocations, vacancies, and vacancy clusters, was studied using positron annihilation lifetime spectroscopy (PALS) [25]. The measurements were carried out with the pulsed low-energy positron beam system (PLEPS) [26, 27] at the high-intensity positron beam source NEPOMUC at the FRM II reactor in Garching. The incident positron energy 

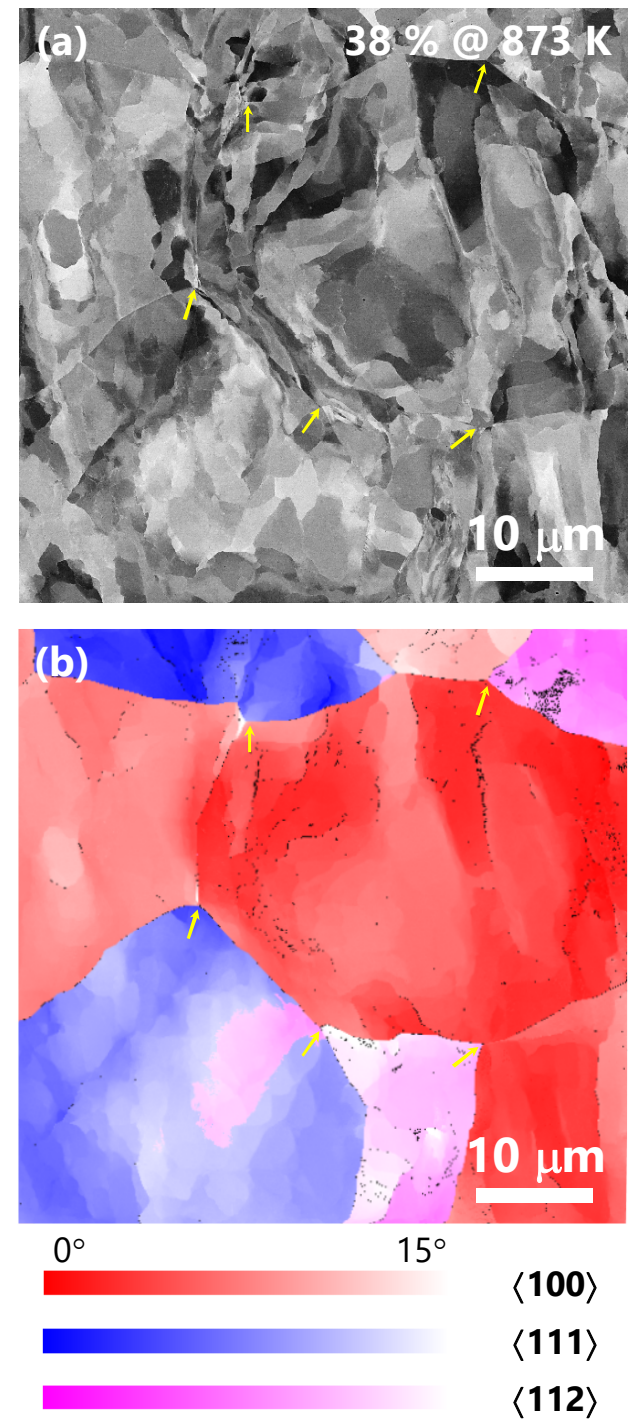

Figure 1. A comparison of (a) a BSE image and (b) an EBSD grain misorientation map for the same area of the surface of recrystallized $\mathrm{W}$ strained to $38 \%$ at $873 \mathrm{~K}$. The misorientation map shows the angular deviation of the crystal orientation from one of the following directions: $\langle 100\rangle$ (red), $\langle 111\rangle$ (blue), and $\langle 112\rangle$ (magenta). Its colour coding is linear with the white colour corresponding to misorientation angles of $15^{\circ}$ and above. The arrows indicate the same places in (a) and (b). The incident electron energy is $20 \mathrm{keV}$.

was $16 \mathrm{keV}$ corresponding to a mean positron implantation depth in $\mathrm{W}$ of $175 \mathrm{~nm}$. The positron implantation profile extends down to about $400 \mathrm{~nm}$. Despite this small positron implantation depth, it is believed that the obtained data are representative for the bulk properties of the samples due to the use of electrochemical polishing as the final surface preparation step (which is expected to remove the artefacts introduced during grinding). The total number of events collected in each positron lifetime spectrum was $4 \times 10^{6}$ to ensure a good counting statistics. The peak-to-background ratio in the spectra was around $10^{4}$. The overall (detector and pulsing system) time resolution 
(FWHM) was 230-250 ps and the count rate was up to $10^{4}$ counts/s. The lifetime spectra were analysed using POSWIN (a modified version of PositronFit [28]) where a model function is fitted to an experimental spectrum. The model function is described by a sum of exponential decays convoluted with an instrumental time resolution function $R(t)$ (determined using a p-type $\mathrm{SiC}$ reference sample) overlaid on a constant background $B G$ : $R(t) * \sum_{i}\left(I_{i} / \tau_{i}\right) \exp \left(-t / \tau_{i}\right)+B G$, where $\tau_{i}$ and $I_{i}\left(\sum_{i} I_{i}=1\right)$ correspond to the positron lifetimes and their relative intensities, respectively. The average positron lifetime is defined as $\tau_{a v}=\sum_{i} I_{i} \tau_{i}$. All measured spectra were decomposed with three lifetime components to obtain good variance with a reduced $\chi_{r}^{2} \leq 1.2$.

\subsection{Deuterium plasma exposure}

In order to decorate the introduced defects with $\mathrm{D}$, the samples were exposed to a D plasma in the PlaQ setup at IPP [29]. The base pressure in the vessel is close to $2 \times 10^{-6} \mathrm{~Pa}$ and the $\mathrm{D}_{2}$ gas pressure during the plasma operation is $1 \mathrm{~Pa}$. The plasma is generated in an electron-cyclotron resonance discharge confined in a stainless steel cage. The plasma beam expands through an aperture in the bottom of the cage and reaches the sample holder. The incident $\mathrm{D}$ ion flux consists predominantly of $\mathrm{D}_{3}^{+}$ions $(94 \%)$ with small contributions of $\mathrm{D}_{2}^{+}(3 \%)$ and $\mathrm{D}^{+}(3 \%)$ ions. A DC bias voltage of $-15 \mathrm{~V}$ was applied to the target holder during the plasma exposures. Taking into account the plasma potential of $-15 \mathrm{~V}$, this results in a mean incident particle energy of $10 \mathrm{eV} / \mathrm{D}$. The absolute value of the ion flux is close to $10^{20} \mathrm{D} / \mathrm{m}^{2} \mathrm{~s}$. The specimens of all types were tightly pressed to the $\mathrm{W}$-coated copper holder at the same radial distance from its centre ensuring identical exposure conditions. A radial scan of the ion saturation current using a Langmuir probe biased to $-50 \mathrm{~V}$ located $3 \mathrm{~cm}$ above the holder indicates that the ion flux decays almost linearly from the innermost to the outermost sample edge by $22 \%$. The holder temperature during the exposures was monitored using a K-type thermocouple attached to it from the back side and was feedback-controlled by using an open-circuit thermostat with silicone oil. The exposures were carried out at sample temperatures of $370 \mathrm{~K}$ and $450 \mathrm{~K}$ to a fluence of $2.4 \times 10^{25} \mathrm{D} / \mathrm{m}^{2}$. After finishing the plasma exposure, the samples were cooled down in vacuum to room temperature within $30 \mathrm{~min}$.

\subsection{Deuterium retention analyses}

D concentration profiles in the samples up to a depth of $7 \mu \mathrm{m}$ were measured using $\mathrm{D}\left({ }^{3} \mathrm{He}, \mathrm{p}\right) \alpha$ nuclear reaction analysis (NRA) at the $3 \mathrm{MV}$ tandem accelerator at IPP. Six different ${ }^{3} \mathrm{He}$ energies varying from $0.69 \mathrm{MeV}$ to $4.5 \mathrm{MeV}$ were used in order to achieve a reasonable depth resolution throughout the whole analysed depth [30]. Reconstruction of $\mathrm{D}$ depth distributions from the measured energy spectra of protons was done using the unbiased, automated procedure implemented in the programme NRADC [31]. NRADC employs SIMNRA 7 [32] for simulation of the proton spectra using the cross-section data from Wielunska et al. [33]. It further applies Bayesian statistics to find the most likely 
depth profile given the data with the least amount of free parameters. As described in detail in [31, the programme first finds the most probable number $N_{\text {best }}$ of layers and then searches for the best depth sampling and concentrations using a MarkovChain (MC) to sample the configuration space spanned by the layer thicknesses and concentrations. In a recent upgrade of the programme, a new method for representing the statistical information accumulated during the $\mathrm{MC}$ was introduced. Once the MC is assumed to have converged, a subset ( $\approx 10^{5}$ samples) of depth profiles samples (DPS) are sampled from this final distribution of compositions and are stored to a disk. In a postprocessing step the cumulative probability density function (CDF) of the concentrations in each of the $N_{\text {best }}$ layers is derived from the DPS: First, a subset $(\approx 30 \%)$ of the DPS are randomly chosen thus yielding a set of independent depth profile samples $\widetilde{\mathrm{DPS}}$. Then for each layer the concentrations occurring in $\widetilde{\mathrm{DPS}}$ are sorted in ascending order and the number of occurrence of the $i$-th concentration value $\eta_{i}$ is determined. After normalising by $\alpha=\sum_{i} \eta_{i}$ then the vector $\mathrm{CDF}_{i}=\eta_{i} / \alpha$ is the CDF of the concentrations in the layer. From the CDF a lower and an upper confidence values for the concentration (i.e., error bars) can be derived. The user has to choose a lower $\mathrm{CDF}_{\mathrm{LOW}}$ and an upper $\mathrm{CDF}_{\mathrm{UPPER}}$ levels in the CDF. The lower error bar $C_{\min }$ then corresponds to the concentration corresponding to $\mathrm{CDF}_{\mathrm{LOW}}$ and the upper error bar $C_{\max }$ is derived analogously from $\mathrm{CDF}_{\text {UPPER. }}$. For example, if the concentrations were following a Gaussian distribution with width $\sigma$, the choosing $\mathrm{CDF}_{\mathrm{LOW}}=0.16$ and $\mathrm{CDF}_{\text {UPPER }}=0.84$ would lead to $\mathrm{a} \pm 1 \sigma$ error bar. However, often the concentrations show multivariate distributions which can still be reasonably characterised applying this CDF-based procedure. In this paper $\mathrm{CDF}_{\mathrm{LOW}}=0.16$ and $\mathrm{CDF}_{\mathrm{UPPER}}=0.84$ were applied.

The $\mathrm{D}$ binding states in the defects were identified using thermal desorption spectroscopy (TDS) in the TESS facility at IPP [34]. The samples were placed in a quartz tube and heated by radiation from an external oven up to a temperature of $1330 \mathrm{~K}$ at a base pressure of about $10^{-6} \mathrm{~Pa}$. The oven was heated linearly with a ramp of $0.25 \mathrm{~K} / \mathrm{s}$ and was feedback-controlled with a thermocouple measuring the oven temperature. The sample temperature versus the oven temperature was calibrated in independent experiments by a K-type thermocouple spot-welded to one of the used samples. The reproducibility of the temperature calibration for different samples of the same type was checked several times and was within $20 \mathrm{~K}$. Ten masses $(\mathrm{m} / z=$ 2-4, 17-20, 28, 32, 44) were monitored by a quadrupole mass-spectrometer (QMS) with a secondary electron multiplier operating in single ion counting mode. The QMS signal of $\mathrm{D}_{2}$ molecules was quantified after each measurement using a calibrated leak bottle with the stated accuracy of $4.6 \%$. The relative QMS sensitivity of HD to $\mathrm{D}_{2}$ molecules was determined prior to the experimental campaign by measuring HD and $\mathrm{D}_{2}$ calibration factors using the following procedure. $\mathrm{HD}\left(\mathrm{D}_{2}\right)$ gas was admitted into the QMS chamber through an aperture of known size from a small volume where the gas pressure is measured by a spinning rotor gauge [35]. The calibration factors for $\mathrm{HDO}$ and $\mathrm{D}_{2} \mathrm{O}$ molecules were estimated based on the assumption that the ratios of the calibration factors of $\mathrm{D}_{2} \mathrm{O}$ to $\mathrm{D}_{2}$ and of $\mathrm{HDO}$ to $\mathrm{HD}$ are the same as that of $\mathrm{H}_{2} \mathrm{O}$ 
to $\mathrm{H}_{2}$ of 0.88 , as reported in [36]. The total $\mathrm{D}$ retention was calculated as the sum of the $\mathrm{D}_{2}$ and $\mathrm{HD}$ contributions. The amount of $\mathrm{D}$ released in the form of $\mathrm{HDO}$ and $\mathrm{D}_{2} \mathrm{O}$ molecules was considered as the upper bound error of the D inventory measurement.

In between different analyses the samples were stored in a vacuum desiccator in order to minimise the negative effects related with prolonged air exposure of the samples 37.

\section{Material characterization}

\subsection{Microstructure evolution}

SEM and EBSD inivestigations reveal that the undeformed recrystallized $\mathrm{W}$ has large isotropic grains with dimensions up to $50 \mu \mathrm{m}$ that are separated mostly by high-angle grain boundaries (Figs. 2(a) and 3(a)). The grains have predominantly $\{100\}$ planes oriented parallel to the surface. A TEM image of the recrystallized $\mathrm{W}$ is shown in Fig. 4(a). A stitched TEM image of the sample can be found in the supplementary material (Fig. S2). In the recrystallized material dislocations appear mostly as short and straight isolated lines and exhibit an inhomogeneous spatial distribution. The measured average dislocation density in the grain interior is $(5.1 \pm 1.7) \times 10^{12} \mathrm{~m}^{-2}$. These results agree with the ones for a similar W grade previously reported by Manhard et al. [5].

After the deformation to low strains $(3 \%$ at $573 \mathrm{~K}$ and $5 \%$ at $873 \mathrm{~K}$ ) the sizes of the grains do not change. The presence of lattice distortion in most of the grains is visible in BSE images as a non-uniform grey level within a grain (Figs. 2(b) and (c)). In EBSD orientation maps, however, these distortions are not visible (Figs. 3(b) and (c)) confirming the higher sensitivity of BSE imaging to very small orientation variations. TEM investigations reveal that these deformations result in the increase of the number and the average length of dislocations in the grain interiors (Figs. 4(b) and (c)). Stitched TEM images of these specimens can be found in the supplementary material (Figs. S3 and S4). The lateral distribution of dislocations is inhomogeneous in both specimens. Apart from isolated dislocation lines, tangles of dislocations are present and are more dense in W strained to $3 \%$ at $573 \mathrm{~K}$. Dislocation agglomerations near grain boundaries are also visible (Figs. S7 and S8), which can be attributed to the influence of two factors: grain boundaries are obstacles for dislocation motion and can also act as dislocation sources [38]. The average dislocation densities (in the grain interior) are almost the same in both specimens: $(1.4 \pm 0.1) \times 10^{13} \mathrm{~m}^{-2}$ in the sample strained to $3 \%$ at $573 \mathrm{~K}$ and $(1.2 \pm 0.3) \times 10^{13} \mathrm{~m}^{-2}$ in the sample strained to $5 \%$ at $873 \mathrm{~K}$.

At medium strains ( $20 \%$ at $573 \mathrm{~K}$ and $22 \%$ at $873 \mathrm{~K}$ ) the dimensions of the grains do not change significantly. The subdivision of the grains into misoriented regions is clearly visible both by SEM (Figs. 2(d) and (e)) and EBSD (Figs. 3(d) and (e)). TEM analysis of these samples has not been done.

At high strains $(36 \%$ at $573 \mathrm{~K}$ and $38 \%$ at $873 \mathrm{~K}$ ) the grain subdivision is even 


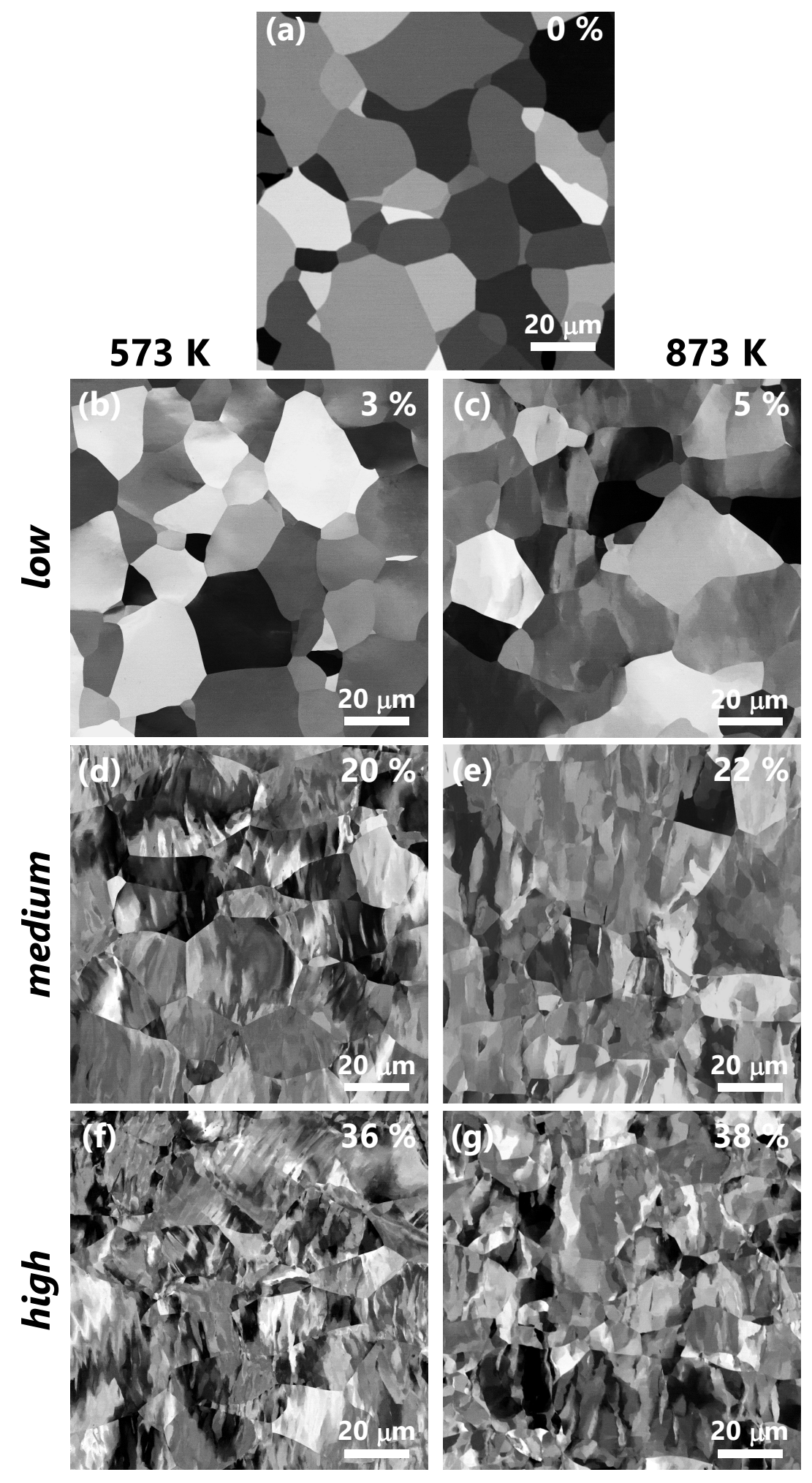

Figure 2. BSE images of the surfaces of recrystallized W: (a) undeformed; (b) strained to $3 \%$ at $573 \mathrm{~K}$; (c) strained to $5 \%$ at $873 \mathrm{~K}$; (d) strained to $20 \%$ at $573 \mathrm{~K}$; (e) strained to $22 \%$ at $873 \mathrm{~K}$; (f) strained to $36 \%$ at $573 \mathrm{~K}$; (g) strained to $38 \%$ at $873 \mathrm{~K}$. The horizontal direction coincides with the tensile loading direction. 


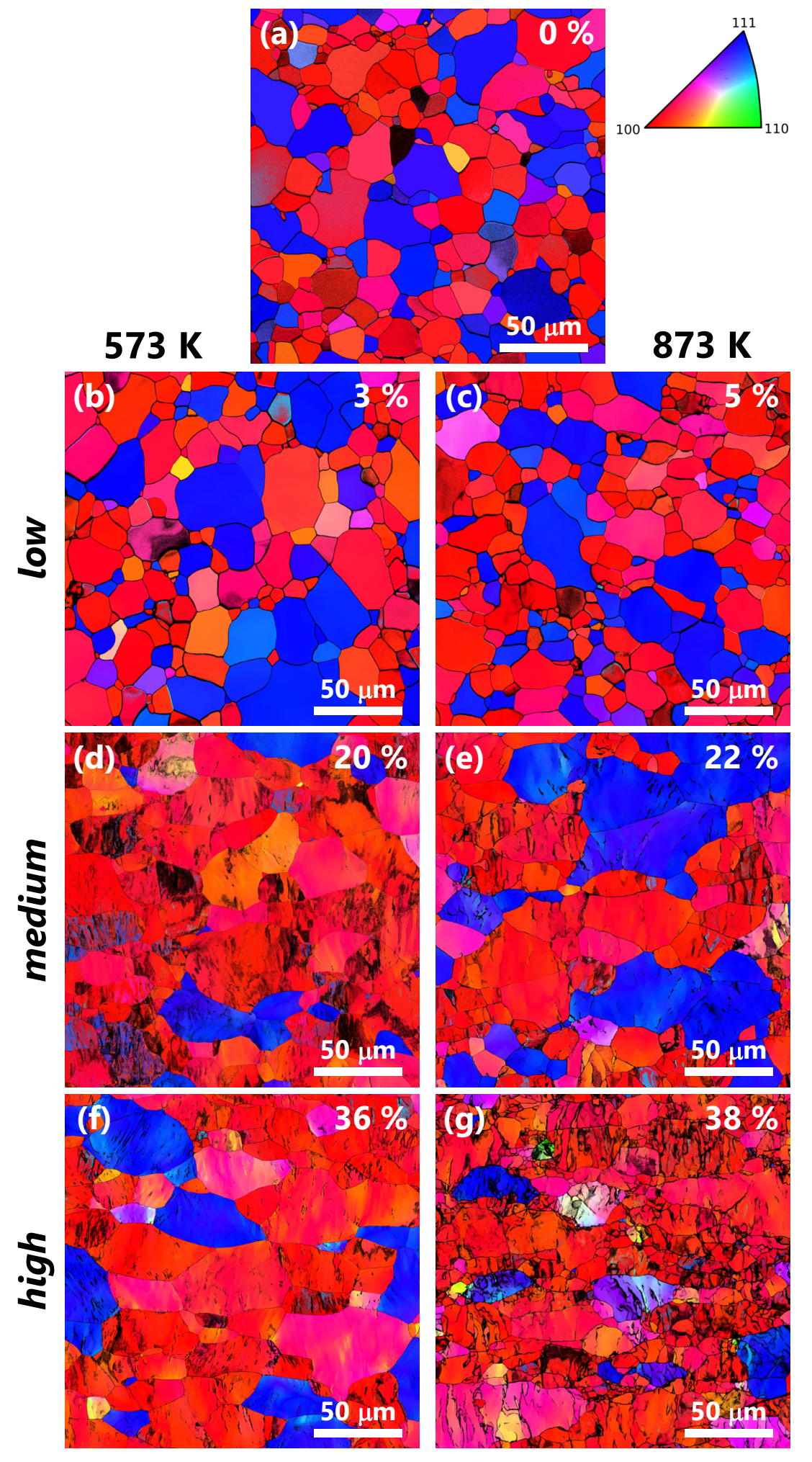

Figure 3. EBSD orientation maps of the surfaces of recrystallized W: (a) undeformed; (b) strained to $3 \%$ at $573 \mathrm{~K}$; (c) strained to $5 \%$ at $873 \mathrm{~K}$; (d) strained to $20 \%$ at $573 \mathrm{~K}$; (e) strained to $22 \%$ at $873 \mathrm{~K}$; (f) strained to $36 \%$ at $573 \mathrm{~K}$; (g) strained to $38 \%$ at $873 \mathrm{~K}$. The colour coding is defined in the standard triangle and is related to the normal direction. The horizontal direction coincides with the tensile loading direction. 


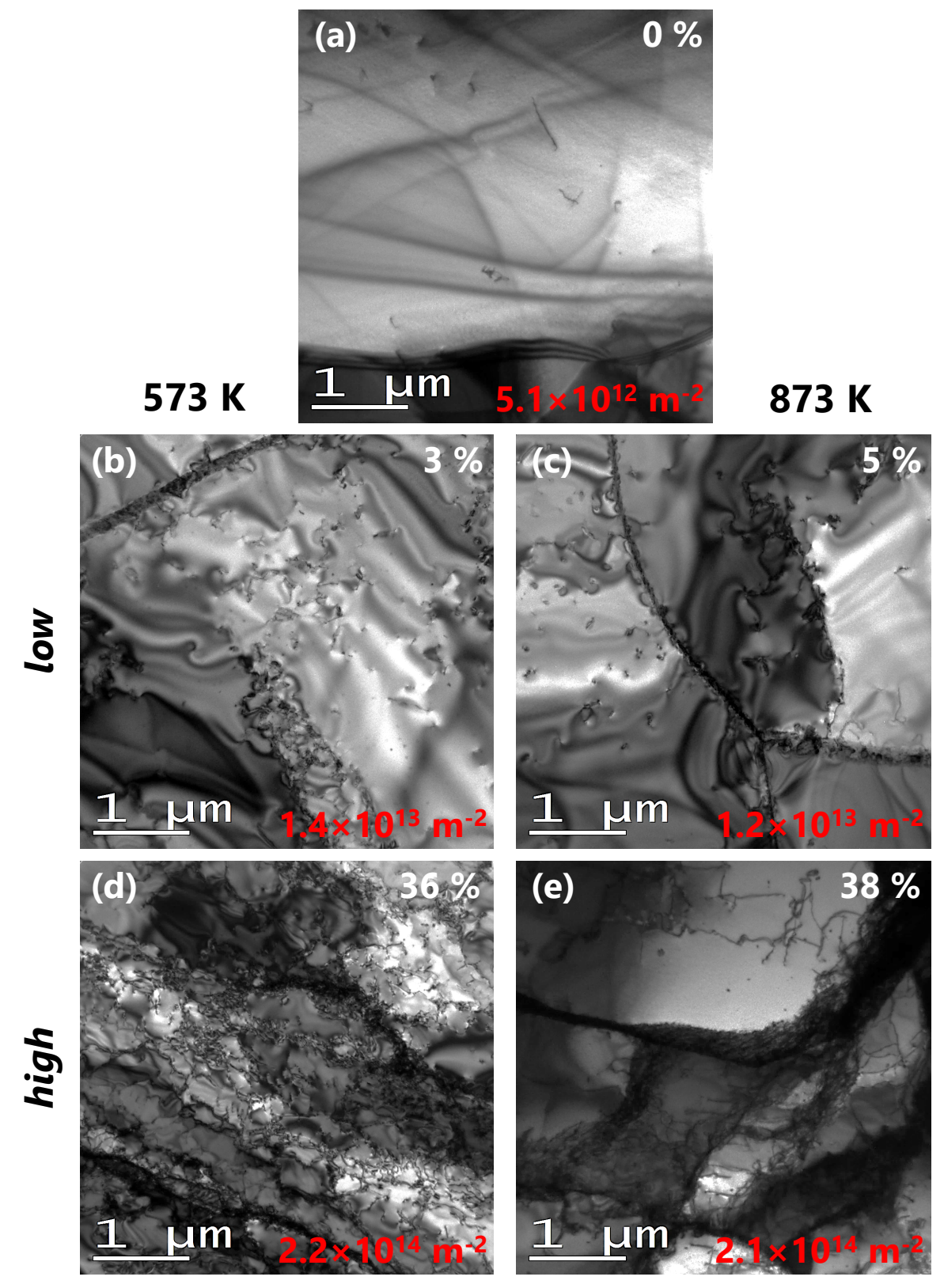

Figure 4. TEM bright field images of recrystallized W: (a) undeformed; (b) strained to $3 \%$ at $573 \mathrm{~K}$; (c) strained to $5 \%$ at $873 \mathrm{~K}$; (d) strained to $36 \%$ at $573 \mathrm{~K}$; (e) strained to $38 \%$ at $873 \mathrm{~K}$. The measured average dislocation densities in the grain interior are indicated for each sample. The broad blurred dark lines in the images are the bend contours due to stresses in the TEM specimens.

more pronounced both in BSE images (Figs. 2(f) and (g)) and EBSD orientation maps (Figs. $3(\mathrm{f})$ and $(\mathrm{g})$ ). The grains also become elongated along the tensile direction. TEM investigations of the material strained to $38 \%$ at $873 \mathrm{~K}$ (Figs. 4 (e) and S10) detect the arrangement of dislocation tangles in walls (cellular substructure), which typically form low-angle grain boundaries [18, 38]. The increase of the dislocation density inside the grains is also apparent and most of the dislocations are tangled, albeit still some 
regions nearly free of dislocations are present. In the material strained to $36 \%$ at $573 \mathrm{~K}$ (Figs. 4(d) and S9) the formation of a cellular substructure is also visible, but the thicknesses of the dislocation walls are smaller compared with those observed in the sample strained at $873 \mathrm{~K}$, and slightly more dislocations are present in the cell interior. It has been also observed in other metals that deformation at lower temperatures results in more homogeneous spatial distribution of dislocations [38. Stitched TEM images of these specimens can be found in the supplementary material (Figs. S5 and S6). The measured average dislocation densities (in the grain interior) are again almost the same in both materials: $(2.2 \pm 0.3) \times 10^{14} \mathrm{~m}^{-2}$ in the sample strained to $36 \%$ at $573 \mathrm{~K}$ and $(2.1 \pm 0.3) \times 10^{14} \mathrm{~m}^{-2}$ in the sample strained to $38 \%$ at $873 \mathrm{~K}$. These dislocation densities are comparable with that in as-received hot-rolled $\mathrm{W}$ of $(3.2 \pm 1.7) \times 10^{14} \mathrm{~m}^{-2}$ [5], as well as with that in recrystallized $\mathrm{W}$ irradiated by $20 \mathrm{MeV} \mathrm{W}$ ions to $0.23 \mathrm{dpa}$ [39]. Note that Manhard et al. [5] counted not only dislocations in the grain interior (like in the present work), but also dislocation agglomerations near grain boundaries and dislocation walls.

Overall, the dislocation density in the samples increases non-linearly with the strain: The dislocation multiplication rate increases with increasing strain.

Previous investigations of the plastic deformation at $873 \mathrm{~K}$ of recrystallized double forged W reported by Terentyev et al. [40] revealed that the dislocation lines observed in the non-deformed and the $5 \%$ deformed material are screw dislocations with a Burgers vector $\mathbf{b}=(1 / 2)\langle 111\rangle$. The dislocation tangles that were observed in highly-deformed samples (above $20 \%$ strain) contained both screw and edge segments.

\subsection{Positron annihilation analysis}

Fig. 5 shows the strain dependences of the positron annihilation parameters in the samples. The impact of strain and deformation temperature is evident already from the raw spectra (see Fig. S11 in the supplementary material) and from the behaviour of the average positron lifetime.

The lifetime spectrum of the undeformed sample is dominated by the shortest component, a reduced bulk lifetime originating from positron annihilation in the defectfree bulk and disappearance from the bulk via trapping into defects. The second lifetime of 157 ps has a $38 \%$ contribution. With increasing strain the intensity of the second lifetime increases, being more rapid in the case of deformation at $573 \mathrm{~K}$. The lifetime itself varies from 162 ps to 175 ps, indicating that the nature of the defects remains similar. This will be further discussed in section 5. The longest lifetime in all samples varies in the range of 460-500 ps, approaching the theoretical limit of the positron lifetime in a cavity in a metal of 500 ps [41]. Therefore, this component represents positron annihilation in clusters containing about 30 or more vacancies [42, 43]. Its intensity stays within $6-7 \%$ for all samples. 


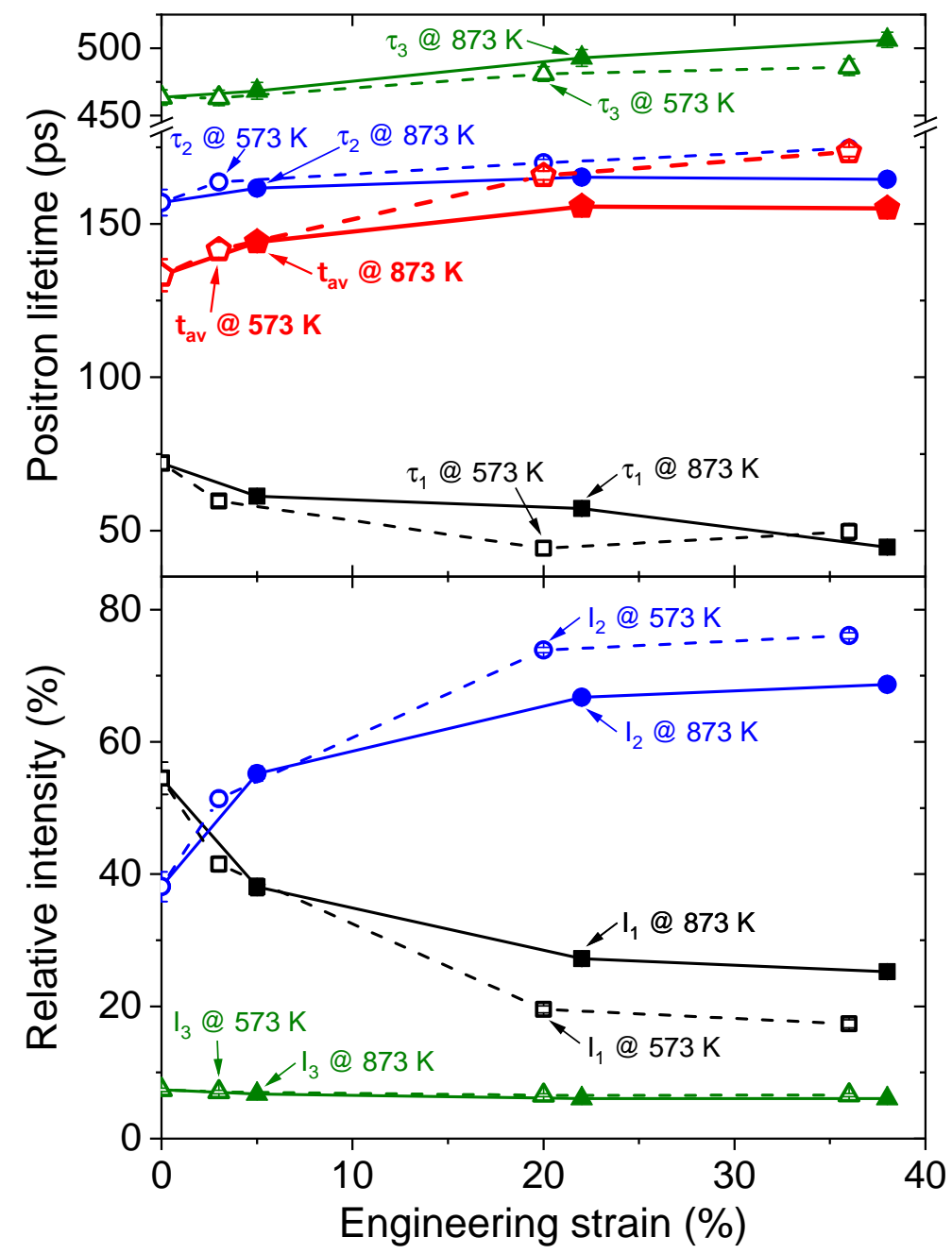

Figure 5. Positron lifetimes $\tau_{i}$ (upper panel) and their relative intensities $I_{i}$ (lower panel) as a function of engineering strain in recrystallized $\mathrm{W}$ deformed at $573 \mathrm{~K}$ (open symbols) and $873 \mathrm{~K}$ (solid symbols). When error bars are not displayed their size is smaller than the symbol size.

\section{Deuterium retention}

\subsection{Plasma exposure at $370 \mathrm{~K}$}

D plasma exposure at $370 \mathrm{~K}$ resulted in the appearance of blister-like structures on all types of samples (Fig. 6). While the number density of these features is very low on the undeformed sample, it noticeably increases already on the samples with low strains. Further increase of the strain to medium and high values results in a rather weak increase of the number density and of the average size of the surface modifications.

The samples deformed to high strains were examined in detail with SEM. Two types of surface modifications, similar to those reported in [44], are present: dome-shaped "blisters" and stepped flat-topped and irregularly-shaped "protrusions". They all have dimensions of a few $\mu \mathrm{m}$. In total, cross-sections of eight structures were examined, 


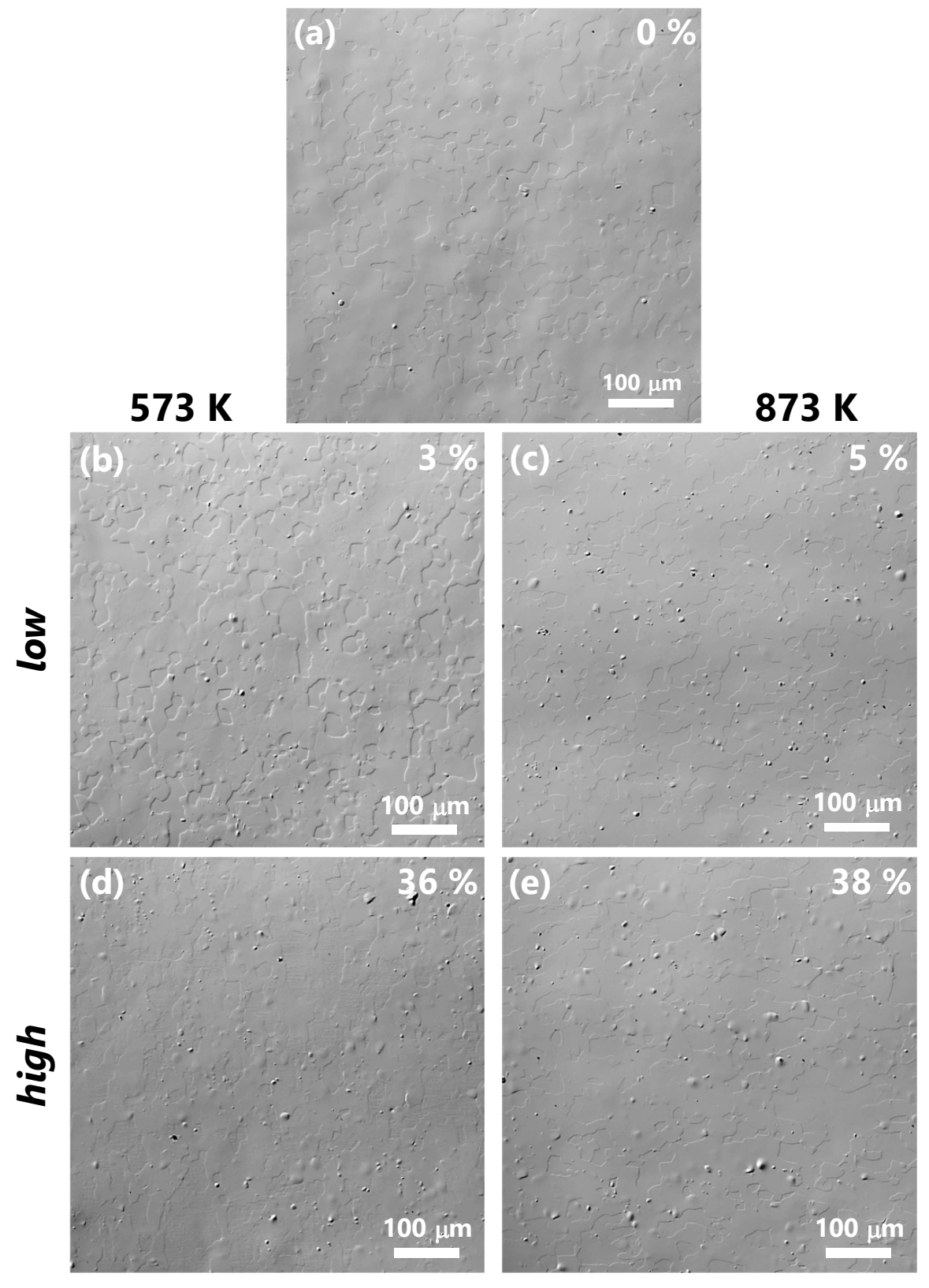

Figure 6. CLSM images (laser intensity image and differential interference contrast) of the surfaces of recrystallized $\mathrm{W}$ exposed to a $\mathrm{D}$ plasma with a mean ion energy of $10 \mathrm{eV} / \mathrm{D}$ to a fluence of $2.4 \times 10^{25} \mathrm{D} / \mathrm{m}^{2}$ at a sample temperature of $370 \mathrm{~K}$ : (a) undeformed; (b) strained to $3 \%$ at $573 \mathrm{~K}$; (c) strained to $5 \%$ at $873 \mathrm{~K}$; (d) strained to $36 \%$ at $573 \mathrm{~K}$; (e) strained to $38 \%$ at $873 \mathrm{~K}$. Note that illumination of the surface appears in the intensity images as coming from the top left edge, i.e., protrusions appear brighter at the top left side while depressions appear darker at the top left side. The visible height differences between the grains are due to the polishing procedure. 

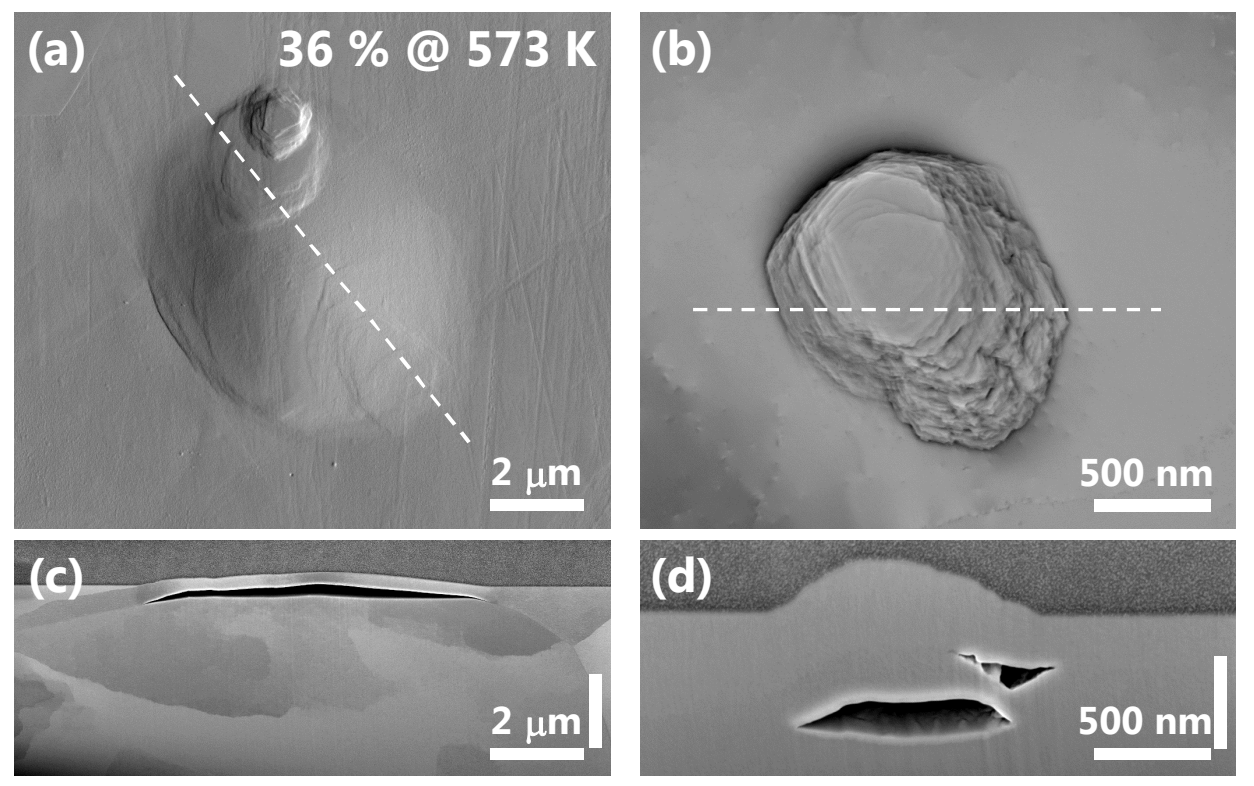

Figure 7. Recrystallized $\mathrm{W}$ strained to $36 \%$ at $573 \mathrm{~K}$ and then exposed to a D plasma with a mean ion energy of $10 \mathrm{eV} / \mathrm{D}$ to a fluence of $2.4 \times 10^{25} \mathrm{D} / \mathrm{m}^{2}$ at a sample temperature of $370 \mathrm{~K}$ : A SEM image of a blister with protrusions on its top; (b) a SEM image of a stepped high-dome protrusion; (c) a SEM image of a cross-section approximately at the position indicated by the dashed line in (a); (d) a SEM image of a cross-section approximately at the position indicated by the dashed line in (b). The images were taken after TDS.

and the cavities of seven of them (both blisters and protrusions) are formed by cracks running along grain boundaries (intergranular), as illustrated in Figs. 7(a) and (c). Only one high-dome protrusion has a cavity formed by a crack within a single grain (transgranular), as shown in Figs. 7(b) and (d). The grain contrast and the fine structure produced by focused ion beam cutting visible in the cross-sectional SEM images suggest that the intergranular cracks are formed along high-angle grain boundaries. Since the significant enhancement of blistering occurs already after deformation to low strains (where no grain fragmentation is visible), it can be linked with the change of the properties of the high-angle grain boundaries during the deformation. This change may be caused, for instance, by the accumulation of dislocations near grain boundaries visible already at low strains. Note that in the present study all samples were polished after the recrystallization. This results in some of the high-angle grain boundaries located very close to the surface (as can be seen in Fig. 7(c)), which is less probable in the case when polishing is done before the recrystallization [12, 44]. This might favour the formation of cavities via intergranular cracking near the surface.

All deformed samples exhibit non-homogeneous D depth distributions, contrary to the undeformed sample (Fig. 8). Concurrently, the depth distribution of the defects introduced by plastic deformation is expected to be (on average) homogeneous through the whole bulk. In addition, the strain dependences of the maximum trapped D concentration and D retention (Fig. 9) are similar to that of the density of surface 


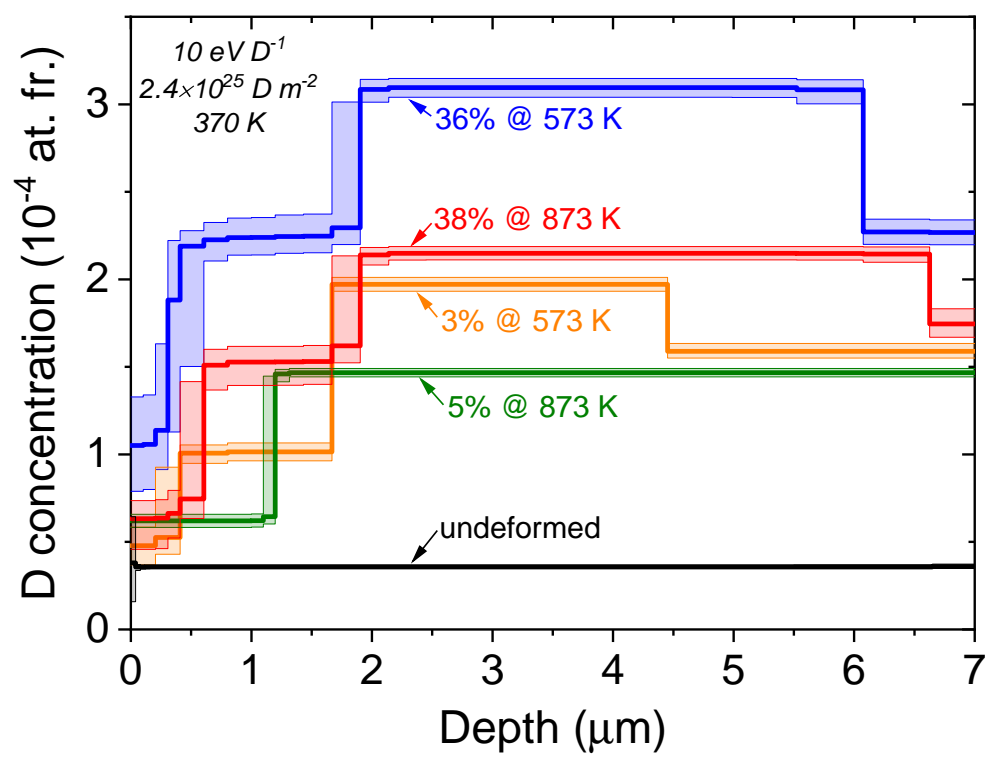

Figure 8. D concentration profiles in recrystallized $\mathrm{W}$ deformed to various strains at $573 \mathrm{~K}$ and $873 \mathrm{~K}$ and then exposed to a D plasma with a mean ion energy of $10 \mathrm{eV} / \mathrm{D}$ to a fluence of $2.4 \times 10^{25} \mathrm{D} / \mathrm{m}^{2}$ at a sample temperature of $370 \mathrm{~K}$.

modifications: fast increase at low strains and then slow increase at high strains. This behaviour is different from that of the dislocation density. It is often discussed in the literature that the emergence of blisters and protrusions in $\mathrm{W}$ introduces defects in the subsurface region that act as trapping sites for D [8, 9, 12, 21, 22]. Therefore, it can be speculated that the observed non-uniform $\mathrm{D}$ concentration profiles are at least partially due to the defects introduced together with blisters and protrusions. It should be mentioned that the cavities of blisters and protrusions were found in a more narrow depth region $(0.3-2.3 \mu \mathrm{m})$ than the depth range with the increased D concentration. However, due to the limited number of investigated surface features, it cannot be excluded that there exist cavities located at larger depths (which even may not have the corresponding surface structures [22]).

TDS spectra from all samples are dominated by the peak with maximum near $700 \mathrm{~K}$ (Fig. 10). Its amplitude is considerably higher in the deformed samples compared with the undeformed one; it also increases with strain for the samples deformed at $873 \mathrm{~K}$, while almost no strain dependence is visible for the samples deformed at $573 \mathrm{~K}$. The amplitudes of the high-temperature shoulders also considerably increase with strain, and this effect is more pronounced for the samples deformed at $573 \mathrm{~K}$. The total D inventories in all samples determined by NRA and TDS are in a reasonable agreement (Fig. 9), indicating that most of the $\mathrm{D}$ is trapped within the first $7 \mu \mathrm{m}$ near the surface.

Overall, the emergence of blisters and protrusions under D plasma exposure at $370 \mathrm{~K}$ and the dependence of their number on the strain does not allow to study the D trapping only by deformation-induced defects. 


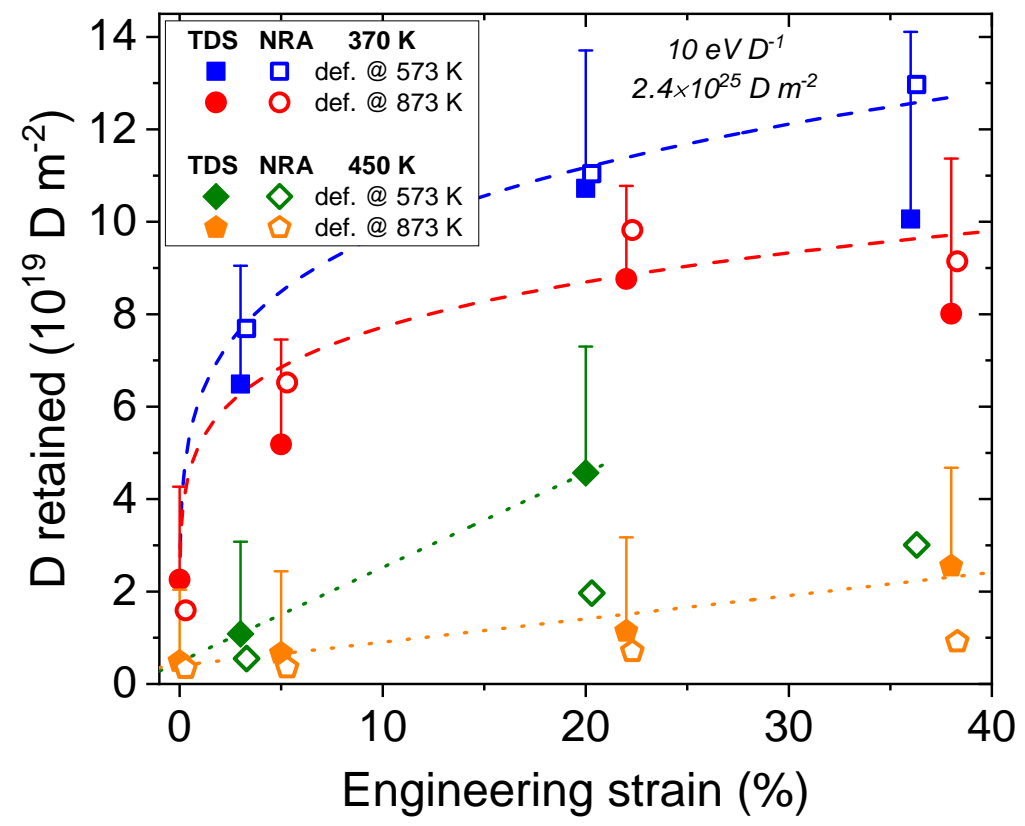

Figure 9. D retention determined by NRA (open symbols) and TDS (solid symbols) in recrystallized $\mathrm{W}$ deformed to various strains at $573 \mathrm{~K}$ and $873 \mathrm{~K}$ and then exposed to a D plasma with a mean ion energy of $10 \mathrm{eV} / \mathrm{D}$ to a fluence of $2.4 \times 10^{25} \mathrm{D} / \mathrm{m}^{2}$ at sample temperatures of $370 \mathrm{~K}$ and $450 \mathrm{~K}$. The error bars represent the estimated amount of $\mathrm{D}$ released as $\mathrm{HDO}$ and $\mathrm{D}_{2} \mathrm{O}$ molecules. Displayed lines are guidelines for the eye only.

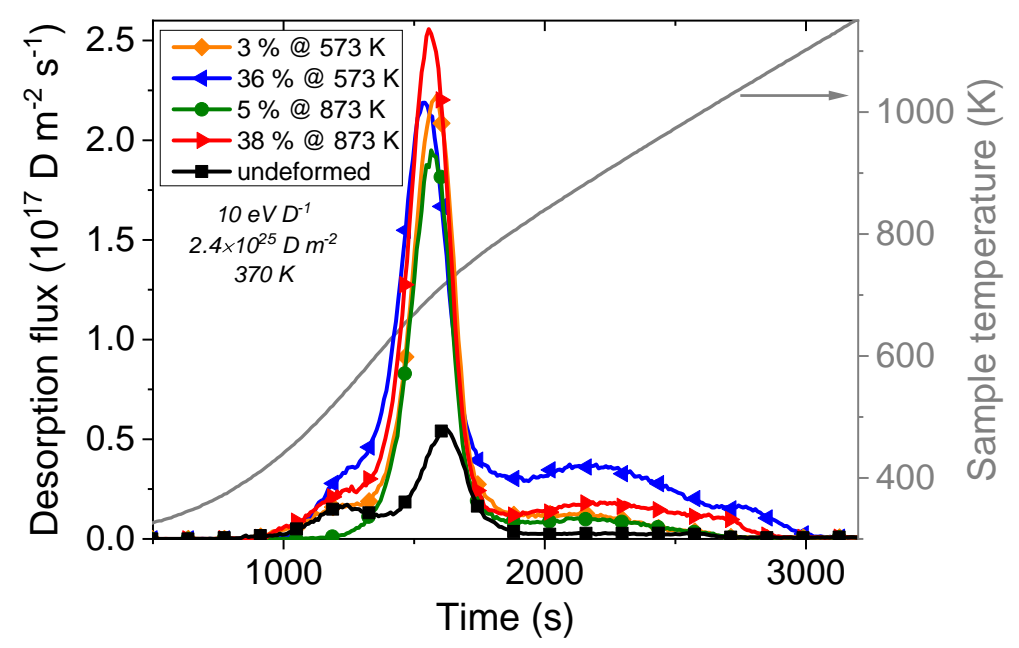

Figure 10. TDS spectra of $\mathrm{D}_{2}$ molecules from recrystallized $\mathrm{W}$ deformed to various strains at $573 \mathrm{~K}$ and $873 \mathrm{~K}$ and then exposed to a D plasma with a mean ion energy of $10 \mathrm{eV} / \mathrm{D}$ to a fluence of $2.4 \times 10^{25} \mathrm{D} / \mathrm{m}^{2}$ at a sample temperature of $370 \mathrm{~K}$. Note that the slight variations in peak positions among different samples can partially be due to the limited heating ramp reproducibility. 


\subsection{Plasma exposure at $450 \mathrm{~K}$}

Increasing the exposure temperature makes the trapping sites with sufficiently low detrapping energies not able to hold D anymore. In addition, the solute $\mathrm{D}$ concentration during the plasma exposure should decrease due to the increased D diffusivity. As a result, the formation of blister-like structures was suppressed on all samples exposed at $450 \mathrm{~K}$.

All samples exhibit flat D depth distributions (Fig. 11) with the concentrations smaller than those after the exposure at $370 \mathrm{~K}$ (compare with Fig. 8). Hence, the number of defects introduced during the plasma exposure at $450 \mathrm{~K}$ should be much smaller compared with that at $370 \mathrm{~K}$ and deformation-induced defects are expected to dominate the $\mathrm{D}$ trapping at $450 \mathrm{~K}$. Nevertheless, for both deformation temperatures the increase of trapped D concentration with strain is smaller than the corresponding increase of the dislocation density in the grain interior.

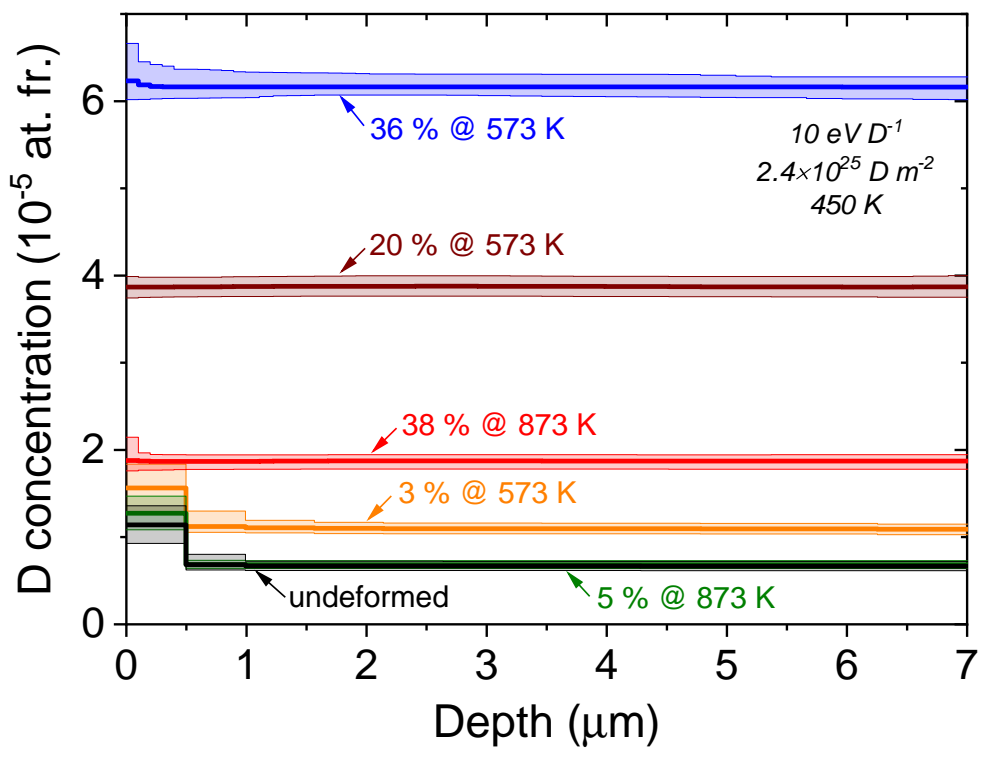

Figure 11. D concentration profiles in recrystallized $\mathrm{W}$ deformed to various strains at $573 \mathrm{~K}$ and $873 \mathrm{~K}$ and then exposed to a D plasma with a mean ion energy of $10 \mathrm{eV} / \mathrm{D}$ to a fluence of $2.4 \times 10^{25} \mathrm{D} / \mathrm{m}^{2}$ at a sample temperature of $450 \mathrm{~K}$.

Fig. 12 shows the TDS spectra after the exposure at $450 \mathrm{~K}$. The spectrum from the sample strained to $36 \%$ at $573 \mathrm{~K}$ could not be measured (the sample got broken during handling), therefore, the spectrum of the sample strained to $20 \%$ at the same temperature is shown. The peak at $650-700 \mathrm{~K}$ is still present, although it is not dominant and its amplitude is considerably smaller as compared with the $370 \mathrm{~K}$ exposure. Such a difference is unlikely due to the increased thermally activated detrapping since this peak is located at much higher temperatures than the sample temperature during the plasma exposure $(450 \mathrm{~K})$. It is more probable that the concentration of the corresponding defects is much smaller in the samples exposed at $450 \mathrm{~K}$. Therefore, the defects corresponding to this peak can be partially related with blisters and protrusions. The high-temperature 


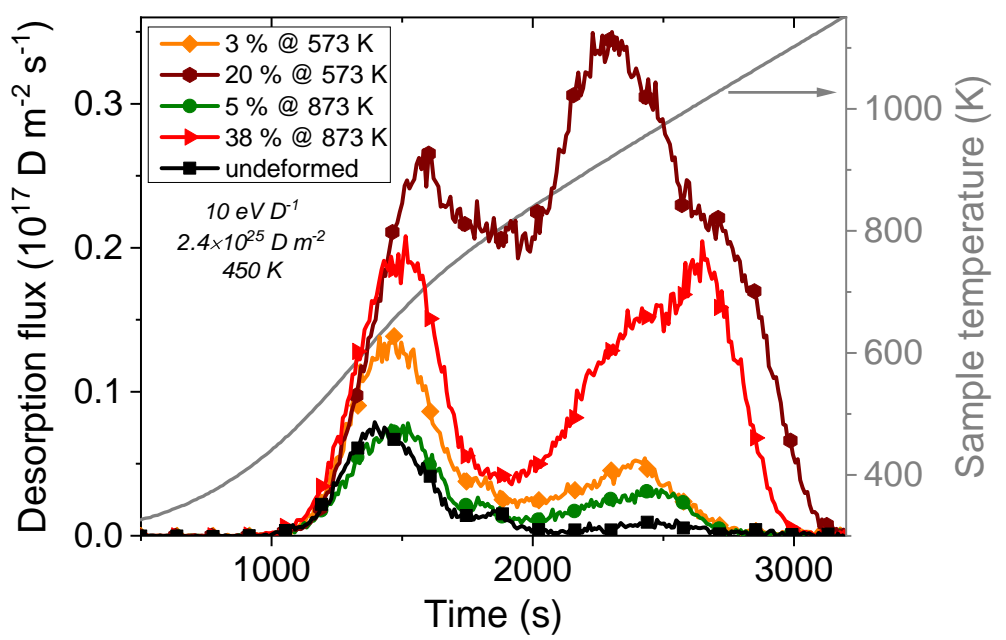

Figure 12. TDS spectra of $\mathrm{D}_{2}$ molecules from recrystallized $\mathrm{W}$ deformed to various strains at $573 \mathrm{~K}$ and $873 \mathrm{~K}$ and then exposed to a D plasma with a mean ion energy of $10 \mathrm{eV} / \mathrm{D}$ to a fluence of $2.4 \times 10^{25} \mathrm{D} / \mathrm{m}^{2}$ at a sample temperature of $450 \mathrm{~K}$. Note that the slight variations in peak positions among different samples can partially be due to the limited heating ramp reproducibility.

peaks/shoulders exhibit a similar strain and deformation temperature dependence as after the exposure at $370 \mathrm{~K}$. The D retention determined from TDS is systematically larger compared with that determined by NRA (Fig. 9), indicating deeper D diffusion into the bulk compared with the $370 \mathrm{~K}$ exposure, albeit the total D inventory is lower.

\section{Discussion}

D plasma exposures both at $370 \mathrm{~K}$, which resulted in the formation of blister-like structures, and at $450 \mathrm{~K}$, when no surface modifications were detected, do not show a linear correlation between the dislocation density and the concentration of trapped D. This is illustrated in Fig. 13 for the case of exposure at $450 \mathrm{~K}$, where D trapping by the deformation-induced defects is expected to dominate. For all variables in Fig. 13 , the shown dependences are normalized by their respective values for the undeformed sample, which allows to reveal their relative increase with strain.

The positron lifetime $\tau_{2}$ in all samples (157-175 ps) is slightly shorter than the reported positron lifetimes in a single vacancy in $\mathrm{W}$ of $180-200 \mathrm{ps}$ [41, 42, 45, 46, 47]. A similar situation has been observed in many plastically-deformed metals [25], including $\mathrm{W}$ [43, 48]. It is commonly accepted that a dislocation core itself is only a shallow trap for positrons [25, 49]. Concurrently, a positron trapped at a dislocation can diffuse along the core and eventually become trapped at a much deeper trap attached to the dislocation. These traps can be jogs and vacancies attached to the dislocation. However, DFT calculations by Staikov and Djourelov [46] predict that a $\langle 100\rangle$ edge dislocation in $\mathrm{W}$ exhibits the positron lifetime of $161 \mathrm{ps}$, which is comparable to $\tau_{2}$. Concurrently, a $(1 / 2)\langle 111\rangle$ screw dislocation has only 130 ps lifetime. The calculated lifetimes for 
a vacancy attached to a dislocation core (equivalent to a pair of jogs with a spacing of one interatomic distance) are very close to that for an isolated vacancy. No lifetime calculations are available for jogs in $\mathrm{W}$. Therefore, $\tau_{2}$ may represent a mixture of positron annihilations in various small open-volume defects having close positron lifetimes, such as jogs, vacancies, and edge dislocation cores.

Jogs on dislocation lines can be formed when two moving dislocations intersect [38, 43, 49]. Vacancies are also supposed to be created during plastic deformation with the help of two mechanisms. First, when two edge dislocations with opposite Burgers vectors meet and their glide planes are separated by one or a few atomic distances, during their annihilation a row of vacancies will be created. Second, movement of a screw dislocation with a jog should result in the creation of a row of either vacancies or interstitial atoms, and the creation of vacancies is favoured due to their lower formation energy. Since in the present study deformations were carried out at temperatures when vacancies in $W$ are mobile, created vacancies can agglomerate in clusters corresponding to the lifetime $\tau_{3}$ [45, 50].

The positron trapping rate into the defects corresponding to the lifetime $\tau_{2}$ computed using the standard positron trapping model (STM) as $\kappa_{2}=I_{2}\left(\tau_{1}^{-1}-\tau_{2}^{-1}\right)$ 25] is also shown in Fig. 13. The positron trapping rate is assumed to be proportional to the defect concentration with the proportionality coefficient named the specific positron trapping rate that depends on the defect type. The specific trapping rates for the defects in W are not well known. STM also assumes a homogeneous spatial defect distribution. This is likely not fulfilled for dislocations in the present samples, especially at high strains (due to the formation of a cellular substructure). However, this assumption may hold for jogs, vacancies, and vacancy clusters. The model applicability was tested by calculating the bulk lifetime as $\tau_{B}=\left(\sum_{i} I_{i} / \tau_{i}\right)^{-1}$ yielding values in the range of $97-$ $112 \mathrm{ps}$ (the only exception is the sample strained to $36 \%$ at $573 \mathrm{~K}$ yielding $125 \mathrm{ps}$ ). These are in fair agreement both with the experimentally determined values and the ones calculated using DFT (101-112 ps) [41, 42, 46, 47, 48] indicating that the defect densities estimated using this model should not be too far off the actual values. As can be seen from Fig. 13, there is no linear correlation between the dislocation density the concentration of the defects corresponding to the lifetime $\tau_{2}$.

Hence, it appears that both the open-volume defects detected by positrons and the defects that determine $\mathrm{D}$ retention at $450 \mathrm{~K}$ do not correspond to dislocations (or at least to their majority). This can be explained by the influence of two factors. The first possibility is that the dislocations (or their majority) are shallow traps for $\mathrm{D}$ that are not able to retain it at $450 \mathrm{~K}$. DFT calculations indeed predict that screw dislocations in W have a low $\mathrm{H}$ detrapping energy $(0.92-0.96 \mathrm{eV})$ and a low positron lifetime (130 ps), while edge dislocations have a considerably higher $\mathrm{H}$ detrapping energy $(1.28-1.36 \mathrm{eV})$ and higher positron lifetime (161 ps) [14, 15, 16, 46]. Unfortunately, it was not possible to quantify the fraction of edge dislocations in the present samples. The other possibility is that, despite the high dislocation density, the corresponding concentration of trapping sites is still very low. Lower limit of the concentration of trapping sites associated with a 


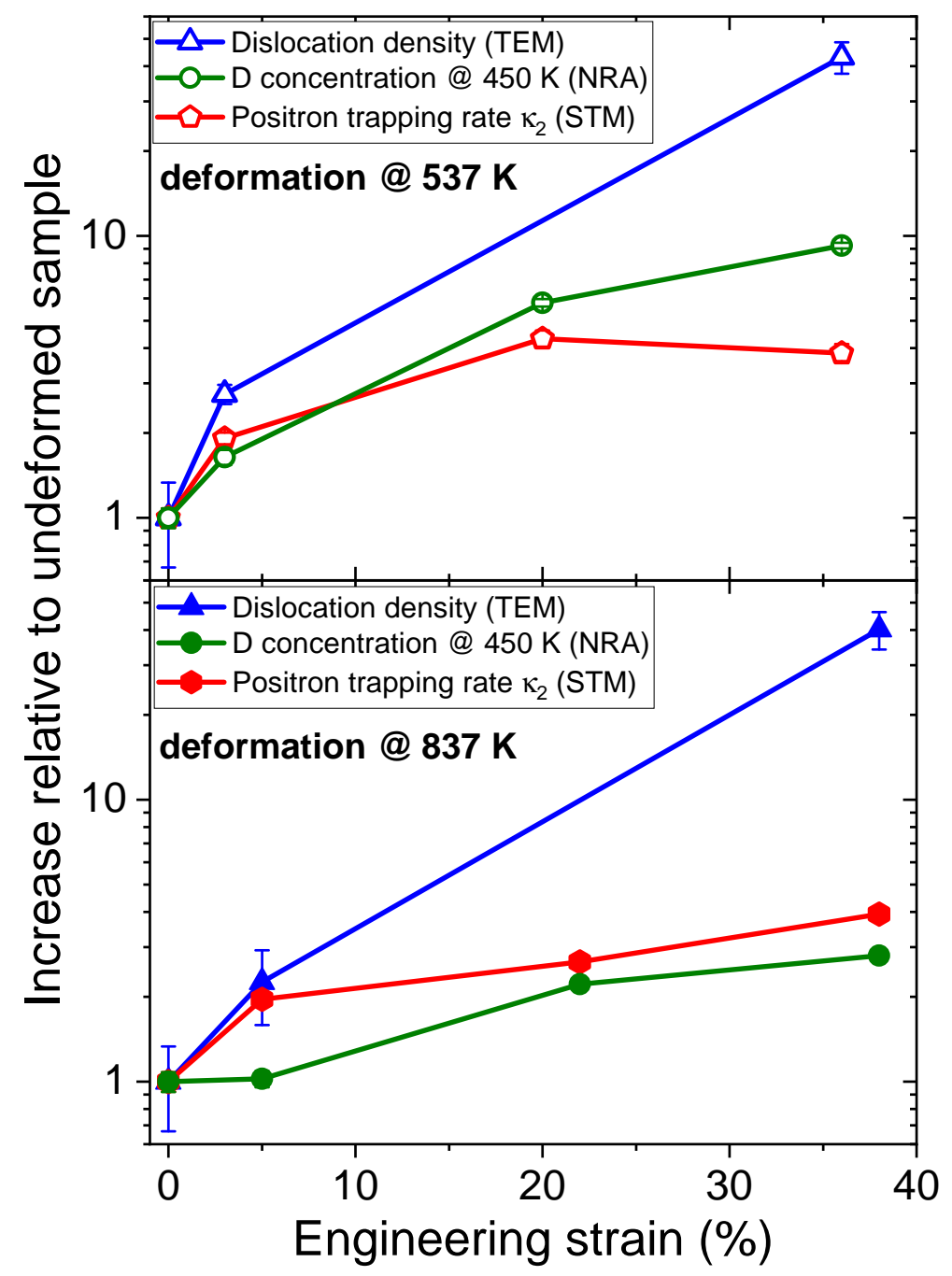

Figure 13. The strain dependence of the trapped D concentration in recrystallized $\mathrm{W}$ deformed at $573 \mathrm{~K}$ (upper panel) and $873 \mathrm{~K}$ (lower panel) and then exposed to a D plasma with a mean ion energy of $10 \mathrm{eV} / \mathrm{D}$ to a fluence of $2.4 \times 10^{25} \mathrm{D} / \mathrm{m}^{2}$ at a sample temperature of $450 \mathrm{~K}$. The strain dependence of the positron trapping rate into the defects corresponding to the dominant lifetime $\tau_{2}$ estimated using the standard trapping model is also shown. The dislocation density in the grain interior measured by TEM as a function of strain is also demonstrated. All the values are normalized by the respective values for the undeformed sample. When error bars are not displayed their size is smaller than the symbol size.

dislocation core can be estimated by assuming one trap per atomic plane perpendicular to the dislocation line and that it can accommodate only one $\mathrm{D}$ atom. That is, the lower limit can be expressed as $N_{\text {disl }}=\rho /\left(a_{W} n_{W}\right)$, where $a_{W}=0.316 \mathrm{~nm}$ is the lattice constant of $\mathrm{W}$ and $n_{W}=6.306 \times 10^{28}$ at. $/ \mathrm{m}^{3}$ is the atomic density of $\mathrm{W}$. The range of dislocation densities $\rho$ (in the grain interior) in the studied samples of $5.1 \times 10^{12}-2.2 \times 10^{14} \mathrm{~m}^{-2}$ then corresponds to the trap concentrations in the range of $2.6 \times 10^{-7}-1.1 \times 10^{-5}$ at. fr. These are indeed lower than the trapped D concentrations in the corresponding samples. Unfortunately, in this study it is not possible to unravel which factor is dominating. 
The TDS spectra of the samples exposed at $450 \mathrm{~K}$ consist of several peaks with amplitudes depending on the strain and the deformation temperature. This shows that several types of trapping sites for $\mathrm{D}$ are present in the deformed $\mathrm{W}$. This is in line with PALS results that detected the presence of both small vacancy-like defects and large vacancy clusters, which should have quite different D detrapping energies [15, 50, 51]. The determined positron trapping rate into large vacancy clusters (not shown in the graph) is much smaller compared with that in small vacancy-like defects and has a weak strain dependence. Note that the specific positron trapping rate into large vacancy clusters increases with increasing cluster size (which cannot be determined from the $\tau_{3}$ value) slower than the number of vacancies in the cluster [52]. Therefore, the correspondence between the positron trapping rate into large vacancy clusters and the associated concentration of trapping sites for D is not straightforward.

Regardless, it is clearly visible that the trapped D concentrations even at high strains are rather low. For instance, they are about two orders of magnitude smaller compared with the trapped $\mathrm{D}$ concentration in radiation-damaged $\mathrm{W}$ at high damage levels (and under similar D loading conditions) [53]. Note that the sample temperatures during the plasma exposures used in the present study $(370 \mathrm{~K}$ and $450 \mathrm{~K})$ are below the operation temperature of most of the $\mathrm{W}$ components in ITER (the minimum temperature is determined by the cooling water inlet temperature of $343 \mathrm{~K}$ ) [1, 2]. Recently Chrominski et al. [39] observed that, despite the different character and density of dislocations (lines and loops) observed in radiation-damaged $\mathrm{W}$ irradiated with different dose rates (to the same damage level), the D retention in the samples was essentially the same already at $295 \mathrm{~K}$. It was concluded that radiation-induced dislocations play a little role in $\mathrm{D}$ retention in $\mathrm{W}$. Hence, at material temperatures relevant for ITER and DEMO trapping at dislocations can be expected to yield a small contribution to $\mathrm{H}$ isotope retention in $\mathrm{W}$.

\section{Conclusions}

The experiments devoted to the investigation of $\mathrm{D}$ interactions with dislocations and other deformation-induced defects in W have been carried out using a set of samples with more than one order of magnitude difference in the dislocation density. The specimens were prepared by tensile deformation of recrystallized $\mathrm{W}$ to various strains (3-38\%) at two different temperatures $(573 \mathrm{~K}$ and $873 \mathrm{~K})$.

D plasma exposure at $370 \mathrm{~K}$ revealed that plastic deformation already to low strains $(3-5 \%)$ results in a significant increase in the number density of emerging blisters and protrusions. Based on TEM observations, it was suggested that the formation of dislocation agglomerations near grain boundaries during the deformation may facilitate blistering. The appearance of these surface modifications presumably resulted in the introduction of additional trapping sites for $\mathrm{D}$ in the material, albeit the trapped D concentrations were quite low (a few times $10^{-4}$ at. fr.).

$\mathrm{D}$ plasma exposure at $450 \mathrm{~K}$ allowed to avoid the formation of these surface 
modifications, resulting in flat $\mathrm{D}$ concentration profiles and smaller $\mathrm{D}$ concentrations (below $10^{-4}$ at. fr.). This suggests that the experimental results were much less affected by the defects introduced during the plasma exposure. The measured dependence of the trapped D concentration on the strain was weaker than the respective increase of dislocation density in the grain interior measured by TEM. PALS analysis detected the presence of small vacancy-like defects and large vacancy clusters which concentration also increased with strain more slowly than the dislocation density. Therefore, the D retention in the deformed samples was likely governed by these defects, while dislocations gave only a small contribution.

Overall, the present experiments indicate that at material temperatures relevant for ITER and DEMO trapping at dislocations in W should yield a small contribution to the tritium inventory.

\section{Acknowledgements}

The technical assistance of T. Dürbeck, K. Eismann, K. Hunger, G. Matern, J. Dorner and M. Fußeder is gratefully acknowledged. Helpful discussions with A. Manhard, W. Pantleon, K. Schlüter and K. Schmid are greatly appreciated. This work was supported by the European Commission and carried out within the framework of the Erasmus Mundus International Doctoral College in Fusion Science and Engineering (FUSION-DC). This work has also been carried out within the framework of the EUROfusion Consortium and has received funding from the Euratom research and training programme 2014-2018 and 2019-2020 under grant agreement No 633053. The work performed under EUROfusion WP PFC. The views and opinions expressed herein do not necessarily reflect those of the European Commission.

\section{References}

[1] T. Hirai, S. Panayotis, V. Barabash, C. Amzallag, F. Escourbiac, A. Durocher, M. Merola, J. Linke, T. Loewenhoff, G. Pintsuk, M. Wirtz, I. Uytdenhouwen, Use of tungsten material for the ITER divertor, Nuclear Materials and Energy 9 (2016) 616-622. doi:10.1016/j.nme.2016.07.003.

[2] G. De Temmerman, T. Hirai, R. Pitts, The influence of plasma-surface interaction on the performance of tungsten at the ITER divertor vertical targets, Plasma Physics and Controlled Fusion 60 (4) (2018) 044018. doi:10.1088/1361-6587/aaaf62.

[3] Y. Ueda, K. Schmid, M. Balden, J. Coenen, T. Loewenhoff, A. Ito, A. Hasegawa, C. Hardie, M. Porton, M. Gilbert, Baseline high heat flux and plasma facing materials for fusion, Nuclear Fusion 57 (9) (2017) 092006. doi:10.1088/1741-4326/aa6b60.

[4] J. Roth, K. Schmid, Hydrogen in tungsten as plasma-facing material, Physica Scripta T145 (2011) 014031. doi:10.1088/0031-8949/2011/T145/014031.

[5] A. Manhard, M. Balden, S. Elgeti, Quantitative microstructure and defect density analysis of polycrystalline tungsten reference samples after different heat treatments, Practical Metallography 52 (8) (2015) 437-466. doi:10.3139/147.110354.

[6] B. Butler, J. Paramore, J. Ligda, C. Ren, Z. Z. Fang, S. Middlemas, K. Hemker, Mechanisms of deformation and ductility in tungsten - a review, International Journal of Refractory Metals and Hard Materials 75 (2018) 248 - 261. doi:10.1016/j.ijrmhm.2018.04.021. 
[7] A. Dubinko, D. Terentyev, A. Bakaeva, M. Hernández-Mayoral, G. D. Temmerman, L. Buzi, J.-M. Noterdaeme, B. Unterberg, Sub-surface microstructure of single and polycrystalline tungsten after high flux plasma exposure studied by TEM, Applied Surface Science 393 (2017) 330 - 339. doi:10.1016/j.apsusc.2016.09.071.

[8] W. Guo, L. Ge, Y. Yuan, L. Cheng, S. Wang, X. Zhang, G.-H. Lu, 〈001〉 edge dislocation nucleation mechanism of surface blistering in tungsten exposed to deuterium plasma, Nuclear Fusion 59 (2) (2018) 026005. doi:10.1088/1741-4326/aaf32e.

[9] A. Manhard, L. Gao, Blisters formed by D plasma exposure in an electron-transparent tungsten sample, Nuclear Materials and Energy 17 (2018) 248 - 252. doi:10.1016/j.nme.2018.11.014.

[10] S. M. Myers, M. I. Baskes, H. K. Birnbaum, J. W. Corbett, G. G. DeLeo, S. K. Estreicher, E. E. Haller, P. Jena, N. M. Johnson, R. Kirchheim, S. J. Pearton, M. J. Stavola, Hydrogen interactions with defects in crystalline solids, Reviews of Modern Physics 64 (1992) 559-617. doi:10.1103/RevModPhys.64.559.

[11] O. Ogorodnikova, J. Roth, M. Mayer, Deuterium retention in tungsten in dependence of the surface conditions, Journal of Nuclear Materials 313-316 (2003) 469 - 477. doi:10.1016/ S0022-3115(02)01375-2.

[12] A. Manhard, Deuterium inventory in tungsten after plasma exposure: a microstructural survey, Ph.D. thesis, Universität Augsburg, Germany (2012). URL http://hdl.handle.net/11858/00-001M-0000-0026-E65B-C

[13] R. Anderl, D. Holland, G. Longhurst, R. Pawelko, C. Trybus, C. Sellers, Deuterium transport and trapping in polycrystalline tungsten, Fusion Technology 21 (1992) 745-752. doi:10.13182/ FST92-A29837.

[14] D. Terentyev, V. Dubinko, A. Bakaev, Y. Zayachuk, W. V. Renterghem, P. Grigorev, Dislocations mediate hydrogen retention in tungsten, Nuclear Fusion 54 (4) (2014) 042004. doi:10.1088/ 0029-5515/54/4/042004.

[15] A. Bakaev, P. Grigorev, D. Terentyev, A. Bakaeva, E. Zhurkin, Y. A. Mastrikov, Trapping of hydrogen and helium at dislocations in tungsten: an ab initio study, Nuclear Fusion 57 (12) (2017) 126040. doi:10.1088/1741-4326/aa7965.

[16] A. D. Backer, D. Mason, C. Domain, D. Nguyen-Manh, M.-C. Marinica, L. Ventelon, C. Becquart, S. Dudarev, Multiscale modelling of the interaction of hydrogen with interstitial defects and dislocations in bcc tungsten, Nuclear Fusion 58 (1) (2018) 016006. doi:doi.org/10.1088/ $1741-4326 / \mathrm{aa} 8 \mathrm{e} 0 \mathrm{c}$

[17] R. Frauenfelder, Solution and diffusion of hydrogen in tungsten, Journal of Vacuum Science and Technology 6 (3) (1969) 388-397. doi:10.1116/1.1492699.

[18] F. Humphreys, M. Hatherly, Recrystallization and Related Annealing Phenomena, second edition Edition, Elsevier, Oxford, 2004. doi:10.1016/C2009-0-64358-0.

[19] D. Terentyev, G. De Temmerman, T. W. Morgan, Y. Zayachuk, K. Lambrinou, B. Minov, A. Dubinko, K. Bystrov, G. Van Oost, Effect of plastic deformation on deuterium retention and release in tungsten, Journal of Applied Physics 117 (8) (2015) 083302. doi:10.1063/1.4913478.

[20] A. Bakaeva, D. Terentyev, G. D. Temmerman, K. Lambrinou, T. Morgan, A. Dubinko, P. Grigorev, K. Verbeken, J. Noterdaeme, Dislocation-mediated trapping of deuterium in tungsten under high-flux high-temperature exposures, Journal of Nuclear Materials 479 (2016) 307-315. doi: $10.1016 / \mathrm{j} \cdot$ jnucmat.2016.07.018

[21] A. Haasz, M. Poon, J. Davis, The effect of ion damage on deuterium trapping in tungsten, Journal of Nuclear Materials 266-269 (1999) 520 - 525. doi:10.1016/S0022-3115(98)00586-8.

[22] Y. Zayachuk, A. Manhard, M. H. J. 't Hoen, W. Jacob, P. A. Zeijlmans van Emmichoven, G. van Oost, Depth profiling of the modification induced by high-flux deuterium plasma in tungsten and tungsten-tantalum alloys, Nuclear Fusion 54 (12) (2014) 123013. doi:10.1088/0029-5515/54/ $12 / 123013$

[23] A. Manhard, G. Matern, M. Balden, A step-by-step analysis of the polishing process for tungsten specimens, Practical Metallography 50 (1) (2013) 5-16. doi:10.3139/147.110215. 
[24] R. K. Ham, The determination of dislocation densities in thin films, Philosophical Magazine 6 (69) (1961) 1183-1184. doi:10.1080/14786436108239679.

[25] J. Čížek, Characterization of lattice defects in metallic materials by positron annihilation spectroscopy: A review, Journal of Materials Science and Technology 34 (4) (2018) 577 - 598. doi:10.1016/j.jmst.2017.11.050.

[26] P. Sperr, W. Egger, G. Kögel, G. Dollinger, C. Hugenschmidt, R. Repper, C. Piochacz, Status of the pulsed low energy positron beam system (PLEPS) at the Munich Research Reactor FRM-II, Applied Surface Science 255 (2008) 35 - 38. doi:10.1016/j.apsusc.2008.05.307.

[27] W. Egger, Pulsed low energy positron beams in materials sciences, IOS Press, Amsterdam, 2010, p. 419. doi:10.3254/978-1-60750-647-8-419.

[28] P. Kirkegaard, J. Olsen, M. Eldrup, PALSfit3: A software package for analysing positron lifetime spectra, Tech. rep., Technical University of Denmark (DTU) (2017).

URL http://orbit.dtu.dk/en/publications/palsfit3-a-software-package-for-analys-ng-positron-lifet .html

[29] A. Manhard, T. Schwarz-Selinger, W. Jacob, Quantification of the deuterium ion fluxes from a plasma source, Plasma Sources Science and Technology 20 (1) (2011) 015010. doi:10.1088/ 0963-0252/20/1/015010.

[30] M. Mayer, E. Gauthier, K. Sugiyama, U. von Toussaint, Quantitative depth profiling of deuterium up to very large depths, Nuclear Instruments and Methods in Physics Research Section B 267 (3) (2009) 506 - 512. doi:10.1016/j.nimb.2008.11.033.

[31] K. Schmid, U. von Toussaint, Statistically sound evaluation of trace element depth profiles by ion beam analysis, Nuclear Instruments and Methods in Physics Research Section B 281 (2012) 64 - 71. doi:10.1016/j.nimb.2012.03.024.

[32] M. Mayer, SIMNRA user's guide, Tech. Rep. IPP 9/113, Max-Planck-Institut für Plasmaphysik, Garching, Germany (1997). URL http://hdl . handle.net/11858/00-001M-0000-0027-6157-F

[33] B. Wielunska, M. Mayer, T. Schwarz-Selinger, U. von Toussaint, J. Bauer, Cross section data for the $D\left({ }^{3} \mathrm{He}, p\right)^{4} \mathrm{He}$ nuclear reaction from 0.25 to $6 \mathrm{MeV}$, Nuclear Instruments and Methods in Physics Research Section B 371 (2016) 41 - 45. doi:10.1016/j.nimb.2015.09.049.

[34] E. Salançon, T. Dürbeck, T. Schwarz-Selinger, F. Genoese, W. Jacob, Redeposition of amorphous hydrogenated carbon films during thermal decomposition, Journal of Nuclear Materials 376 (2) (2008) 160 - 168. doi:10.1016/j.jnucmat.2008.02.070.

[35] P. Wang, W. Jacob, L. Gao, T. Dürbeck, T. Schwarz-Selinger, Comparing deuterium retention in tungsten films measured by temperature programmed desorption and nuclear reaction analysis, Nuclear Instruments and Methods in Physics Research Section B 300 (2013) 54 61. doi:10.1016/j.nimb.2013.01.057.

[36] Relative Sensitivity Measurements of Gases, Gas Analysis Application Note 282, Hiden Analytical.

URL http://www.hiden.de/wp-content/uploads/pdf/RS_Measurement_of_Gases_-_ Hiden_Analytical_App_Note_282.pdf

[37] K. Moshkunov, K. Schmid, M. Mayer, V. Kurnaev, Y. Gasparyan, Air exposure and sample storage time influence on hydrogen release from tungsten, Journal of Nuclear Materials 404 (3) (2010) 174 - 177. doi:10.1016/j.jnucmat.2010.07.011.

[38] D. Hull, D. Bacon, Introduction to Dislocations, 5th Edition, Butterworth-Heinemann, Oxford, 2011. doi:10.1016/C2009-0-64358-0.

[39] W. Chrominski, L. Ciupinski, P. Bazarnik, S. Markelj, T. Schwarz-Selinger, TEM investigation of the influence of dose rate on radiation damage and deuterium retention in tungsten, Materials Characterization 154 (2019) 1 - 6. doi:10.1016/j.matchar.2019.05.028.

[40] D. Terentyev, X. Xiao, A. Dubinko, A. Bakaeva, H. Duan, Dislocation-mediated strain hardening in tungsten: Thermo-mechanical plasticity theory and experimental validation, Journal of the Mechanics and Physics of Solids 85 (2015) 1 - 15. doi:10.1016/j.jmps.2015.08.015. 
[41] A. Seeger, F. Banhart, On the systematics of positron lifetimes in metals, Physica Status Solidi A 102 (1) (1987) 171-179. doi:10.1002/pssa.2211020117.

[42] T. Troev, E. Popov, P. Staikov, N. Nankov, T. Yoshiie, Positron simulations of defects in tungsten containing hydrogen and helium, Nuclear Instruments and Methods in Physics Research Section B 267 (3) (2009) 535 - 541. doi:10.1016/j.nimb.2008.11.045.

[43] J. Č́žžek, O. Melikhova, Z. Barnovská, I. Procházka, R. Islamgaliev, Vacancy clusters in ultra fine grained metals prepared by severe plastic deformation, Journal of Physics: Conference Series 443 (1) (2013) 012008. doi:10.1088/1742-6596/443/1/012008.

[44] M. Balden, A. Manhard, S. Elgeti, Deuterium retention and morphological modifications of the surface in five grades of tungsten after deuterium plasma exposure, Journal of Nuclear Materials 452 (1-3) (2014) 248 - 256. doi:10.1016/j.jnucmat.2014.05.018.

[45] P. E. Lhuillier, M. F. Barthe, P. Desgardin, W. Egger, P. Sperr, Positron annihilation studies on the nature and thermal behaviour of irradiation induced defects in tungsten, Physica Status Solidi C 6 (11) (2009) 2329-2332. doi:10.1002/pssc.200982114.

[46] P. Staikov, N. Djourelov, Simulations of $\langle 100\rangle$ edge and $1 / 2\langle 111\rangle$ screw dislocations in $\alpha$-iron and tungsten and positron lifetime calculations, Physica B: Condensed Matter 413 (2013) 59 - 63. doi:10.1016/j.physb.2012.12.026.

[47] J. Heikinheimo, K. Mizohata, J. Räisänen, T. Ahlgren, P. Jalkanen, A. Lahtinen, N. Catarino, E. Alves, F. Tuomisto, Direct observation of mono-vacancy and self-interstitial recovery in tungsten, APL Materials 7 (2) (2019) 021103. doi:10.1063/1.5082150

[48] T. Staab, R. Krause-Rehberg, B. Vetter, B. Kieback, G. Lange, P. Klimanek, The influence of microstructure on the sintering process in crystalline metal powders investigated by positron lifetime spectroscopy: II. tungsten powders with different powder-particle sizes, Journal of Physics: Condensed Matter 11 (7) (1999) 1787. doi:10.1088/0953-8984/11/7/010

[49] T. Wider, S. Hansen, U. Holzwarth, K. Maier, Sensitivity of positron annihilation to plastic deformation, Physical Review B 57 (1998) 5126-5139. doi:10.1103/PhysRevB.57.5126.

[50] H. Eleveld, A. van Veen, Void growth and thermal desorption of deuterium from voids in tungsten, Journal of Nuclear Materials 212-215 (1994) 1421 - 1425. doi:10.1016/0022-3115(94) 91062-6.

[51] A. van Veen, H. Filius, J. de Vries, K. Bijkerk, G. Rozing, D. Segers, Hydrogen exchange with voids in tungsten observed with TDS and PA, Journal of Nuclear Materials 155-157 (1988) 1113 - 1117. doi:10.1016/0022-3115(88)90478-3.

[52] M. Eldrup, Positron studies of gases and gas bubbles in metals, Materials Science Forum 105 (1992) 229-248. doi:10.4028/www.scientific.net/MSF.105-110.229.

[53] O. Ogorodnikova, V. Gann, Simulation of neutron-induced damage in tungsten by irradiation with energetic self-ions, Journal of Nuclear Materials 460 (2015) 60 - 71. doi:10.1016/j.jnucmat. 2015.02 .004 